\title{
Preliminary Estimates of Specific Discharge and Transport Velocities near Borehole NC-EWDP-24PB
}

Barry Freifeld, Christine Doughty, and Stefan Finsterle

Earth Sciences Division

Lawrence Berkeley National Laboratory

June 2006 


\section{Executive Summary}

This report summarizes fluid electrical conductivity (FEC) and thermal logging data collected in Borehole NC-EWDP-24PB, located approximately $15 \mathrm{~km}$ south of the proposed repository at Yucca Mountain. Preliminary analyses of a small fraction of the FEC and temperature data indicate that relatively large, localized fluid fluxes are likely to exist at this location. The implication that considerable flow is induced by small gradients, and that flow is highly localized, is significant for the estimation of groundwater transport velocities and radionuclide travel times.

The sensitivity of the data to potential perturbations during testing (i.e., internal wellbore flow in the case of FEC data, and buoyancy effects in the case of thermal logging data) make it difficult to conclusively derive fluid fluxes and transport velocities without a detailed analysis of all data and processes involved. Such a comprehensive analysis has not yet been performed. However, the preliminary results suggest that the ambient component of the estimated flow rates is significant and on the order of liters per minute, yielding groundwater transport velocities in the range of kilometers per year. One particular zone in the Bullfrog tuff exhibits estimated velocities on the order of $10 \mathrm{~km} / \mathrm{yr}$.

Given that the preliminary estimates of ambient flow rates and transport velocities are relatively high, and considering the potential impact of high rates and velocities on saturated-zone flow and transport behavior, we recommend that a comprehensive analysis of all the available data be performed. Moreover, additional data sets at other locations should be collected to examine whether the current data set is representative of the regional flow system near Yucca Mountain. 


\section{Introduction}

Borehole NC-EWDP-24PB (24PB) was drilled and completed in February and March of 2006 by the Nye County Nuclear Waste Repository Project Office. Borehole 24PB was developed as part of the Nye County Early Warning Drilling Program and also provides a test bed for the OST\&I project "Field Studies for the Determination of Transport Properties of Radioactive Solutes and Colloids Using Chemical Analogues." The 24PB program includes participation by staff from the Nye County Nuclear Waste Repository Project Office, Lawrence Berkeley National Laboratory, Los Alamos National Laboratory, and the United States Geological Survey. Borehole 24PB is located approximately $15 \mathrm{~km}$ south of the proposed Yucca Mountain repository and $6 \mathrm{~km}$ north of Highway 95 (Figure 1).

Borehole 24PB targeted the Crater Flat Tuff for reactive transport testing because of the unit's importance in saturated zone (SZ) groundwater transport. Prior lithologic information existed from Borehole NC-EWDP-24P, located $30 \mathrm{~m}$ north of $24 \mathrm{~PB}$, and helped guide decision making while drilling 24PB. Drilling of 24PB was halted at $425 \mathrm{~m}$ depth, just below the Tram tuff contact with an underlying volcaniclastic sedimentary unit. Since lithologic interpretation of 24PB drill cuttings is still in progress, the lithologic log from Borehole 24P [Nye County RID 6707] is shown in Figure 2. The $24 \mathrm{~PB}$ water table is located at $120 \mathrm{mbgs}$, at the alluvial/Bullfrog tuff interface. The locations of the Bullfrog tuff/sedimentary interbed/Tram tuff contacts, as determined using the 24PB optical televiewer log, are located at 280 and $288 \mathrm{mbgs}$, approximately 4 to $8 \mathrm{~m}$ deeper than observed in NC-EWDP-24P. The 24PB final completion log, detailing the backfill materials used and the placement of a piezometer and four U-tube groundwater samplers, is shown in Figure 3. 


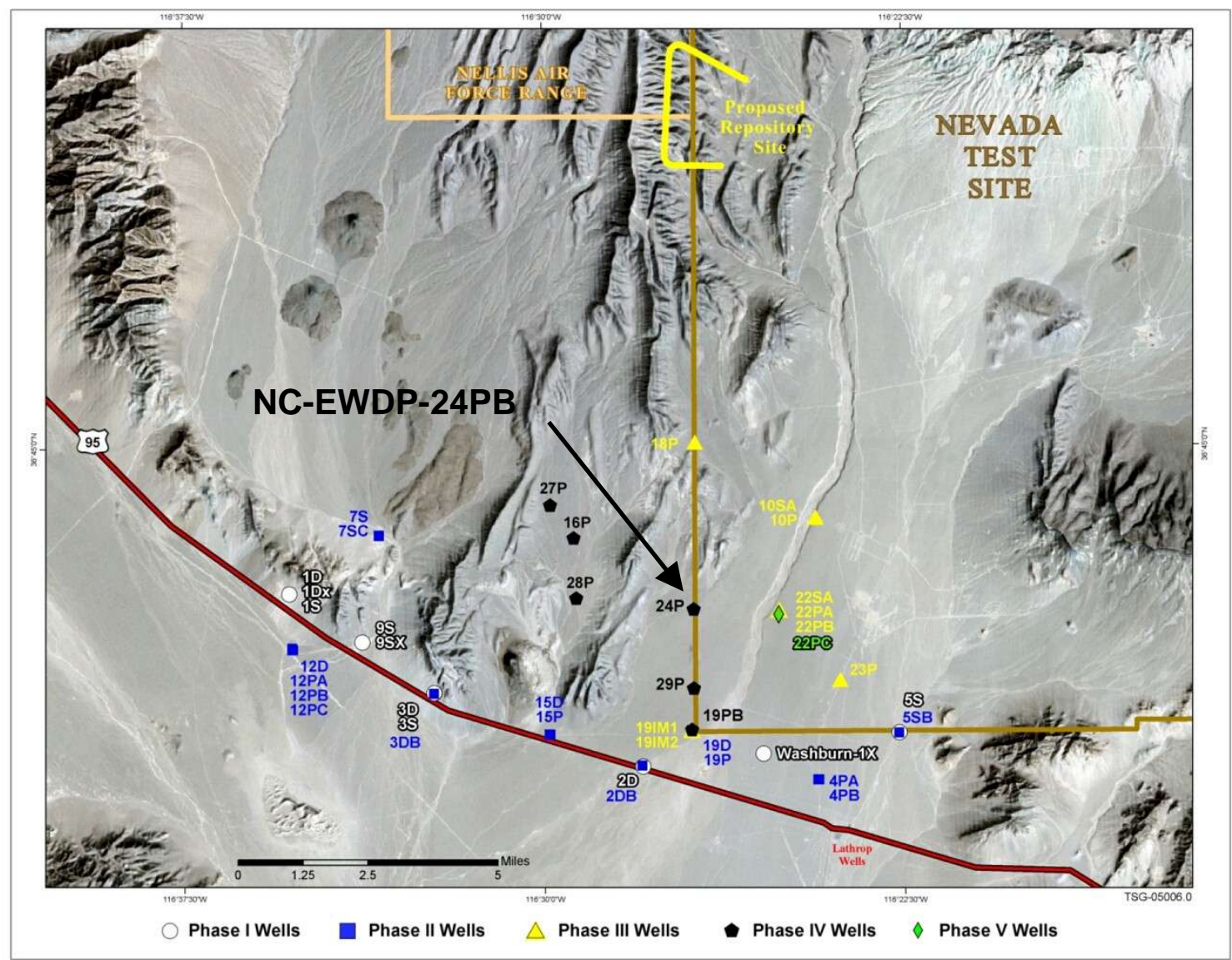

Figure 1. Location of Borehole NC-EWDP-24PB in the Amargosa Valley, approximately $15 \mathrm{~km}$ due south of the proposed repository site and $6 \mathrm{~km}$ north of Highway 95 . Figure courtesy of Nye County NWRPO.

As part of the 24PB drilling program, geophysical logs including gamma, formation resistivity, self-potential, single-point resistivity, and optical televiewer were acquired. In addition to the standard suite of logs, flowing fluid electrical conductivity logs (FEC) were also acquired. The initial goal for collecting flowing FEC logs was to identify hydrologically significant intervals for the placement of the U-tube groundwater sampling systems for reactive transport tests. The FEC logging program was planned to occur over one to two days. However, observations of fluid fluxes that were greater than expected led to the acquisition (between February 24 and February 28, 2006) of an extensive data set, consisting of six distinct tests comprising 30,000 ft of FEC logs collected over 32 runs.

Interpreting the 24PB FEC logs to provide estimates of groundwater fluxes was complicated by the fact that multiple data sets could not be analyzed using a single, simple conceptual model. It was felt that the difficulties in the interpretation were primarily caused by the very high intrinsic permeability of the formation penetrated by 24PB and fluid flow's sensitivity to the open wellbore conditions. While the two primary interpretive approaches yielded what were felt to be either high or very high flux 
estimates, it could not be fully discounted that these observations were an artifact of intraborehole flow.

In addition to FEC, thermal perturbation techniques were used as an independent method for estimating natural fluid flux. The distributed thermal perturbation sensor (DTPS) quantifies fluid flux using temperature transients measured along a borehole under constant heating conditions. Since this technique was employed after the well was backfilled, the effects of intraborehole flow are eliminated.

The FEC and DTPS data sets, although based on different physical processes, are complementary, in that they provide corroborative information that aids in the interpretation of the other data set. Whereas the FEC data precisely identify locations where fluid flow occurs, the DTPS provides estimates of natural fluxes without the uncertainty of open borehole conditions.

This report summarizes the raw data and provides a preliminary interpretation of some of the data collected. Limitations of the data sets and the underlying assumptions will be discussed and suggestions for additional data analysis will be made. In addition, recommendations for acquiring further data sets will be made.

\section{Quality Assurance Information}

The drilling and completion activities of Borehole 24PB, consisting of calibration of measured depths and acquisition of cutting samples, were qualified by the Yucca Mountain Project Sample Management Facility staff. The geophysical logging program, conducted under the auspices of Nye County, was qualified by Nye County, but is not considered qualified data under either the Yucca Mountain or OSTI programs. In addition, the initial acquisition of thermal data was conducted as a scoping activity, and has not been qualified. Repetition of the thermal measurements under the OSTI program is planned so that the new data set can be qualified under Berkeley Laboratory's OSTI QA program. 


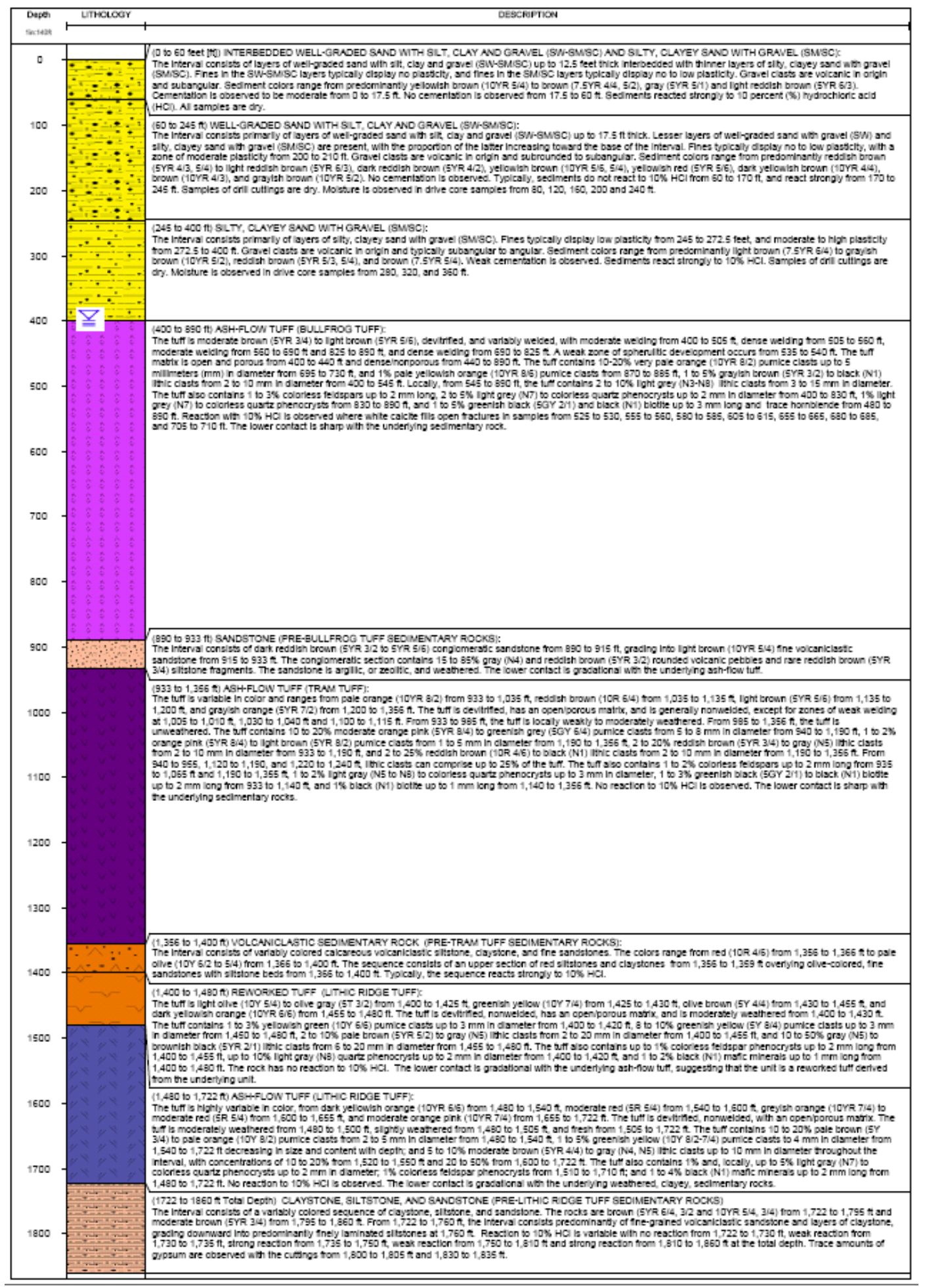

Figure 2. Lithologic log of Borehole NC-EWDP-24P, located $30 \mathrm{~m}$ north of NCEWDP-24PB. Preliminary interpretation of 24 PB logs indicate that lithologic contacts appear in 24PB deeper (by 4 to $8 \mathrm{~m}$ ) than in 24P. [Nye County RID 6707] 


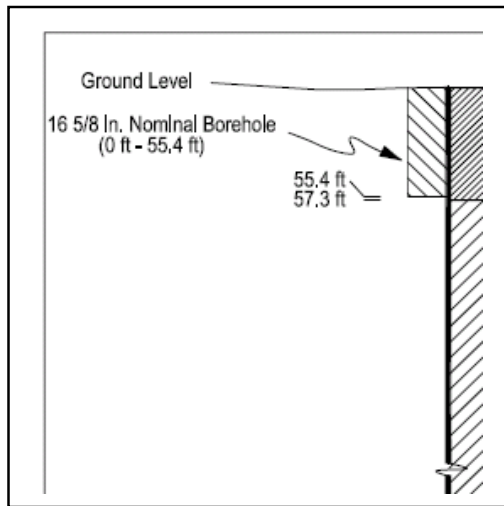

Figure 3. Well completion diagram for NC-EWDP24PB. [Nye County RID 6949] 


\section{Fluid Electrical Conductivity Logging}

Flowing fluid electrical conductivity (FEC) logging provides a valuable means to characterize fractures intersecting a wellbore and the hydrologic behavior of fractured rocks (Tsang, et al., 1990; Tsang and Doughty, 2003; Doughty and Tsang; 2005; Doughty et. al., 2005). This section describes the FEC data and the results of a preliminary analysis of FEC logs, which focused on a subset of the acquired data. Thus, the results and discussions are preliminary and must be considered as work in progress.

Section 3.1 presents an overview of the FEC logging method and describes the BORE II code used to analyze FEC logging data. Details of the experimental set up are described in Section 3.2, followed by the FEC data set itself. Next, Section 3.3 describes the results of the preliminary analysis, including some discussion and caveats. Finally, a discussion of the FEC logging results are given in Section 3.4, and a list of recommendations for further work to be done is presented in Section 6.

\subsection{Overview of FEC Logging Method and BORE II}

In the FEC logging method, wellbore water is first replaced by deionized water or, alternatively, water of a constant salinity distinctly different from that of the formation water. This is done by passing the deionized water down a tube to the bottom of the borehole at a given rate, while simultaneously pumping from the top of the well at the same rate, until the FEC of the water pumped out of the well stabilizes at a low value. This procedure is known as recirculation, which is done in practice by taking the pumped water, running it through a treatment system on site to reduce the salinity, and reinjecting it using a tremmie pipe. Next, the well is shut in (i.e., pumping is stopped) and the tubing is removed or deactivated. Then the well is pumped, usually from the top, at a constant, low flow rate (e.g., tens of liters per minute), while an electrical conductivity probe is lowered into the borehole to record the FEC as a function of depth. This produces what is known as a flowing FEC log. With constant pumping conditions, a series of five or six flowing FEC logs are typically obtained over a one- or two-day period, depending on the length of well section being studied and the formation permeability. At locations where formation water enters the borehole (the feed points), the flowing FEC logs display peaks. These peaks grow with time and are skewed in the direction of water flow within the borehole. By analyzing these logs at successive times, it is possible to obtain the flow rate and salinity of groundwater inflow to the wellbore from individual hydraulically conductive fractures.

In a variation of this method, after recirculation is complete, the well is shut in and logging is done under ambient conditions (no pumping), producing what is known as an ambient FEC log. In this case, if peaks are skewed up or down the wellbore internal wellbore flow is taking place, whereas if peaks simply grow at a given depth, it indicates that formation water is flowing horizontally across the wellbore. For simplicity, we refer to the technique of conducting either flowing FEC logging or ambient FEC logging as 
FEC logging, and will add the terms "flowing" or "ambient" only when required for distinction.

Below, we define some terms we shall be using throughout this document:

Inflows: These are feed points (fractures) where formation water flows into the well, either because water is being pumped from the well, or, in the case of no pumping, the far-field (initial) pressure head is higher than the average pressure head in the well bore.

Outflows: These are feed points (fractures) where water flows out of the well, either because water is being injected into the well (net injection), or, in the case of no pumping, the far-field (initial) pressure head is lower than the average pressure head in the well bore.

Cross flows: These are feed points (fractures) where water flows in on one side of the well and out the other. This happens if there is a strong regional flow in the fracture and its water flows across the cross section of the well. Cross flow is equivalent to having inflow and outflow at the same depth.

Flowing FEC logs or data. After recirculation stops, the well may be pumped at a certain flow rate with a corresponding drawdown in the well, which induces flows in all the inflow points (outflows are either reduced or even transformed into inflows if the pumping rate is high). This produces a series of FEC logs with peaks that grow with time and move up the wellbore.

Internal Flow: This is upward or downward flow in the borehole, arising from the inflows and outflows at various depths, that may occur when the well is shut in.

Recirculation FEC logs. This is the FEC log that is obtained when injecting deionized water deep into the well while pumping at the same rate at a much shallower depth, just below the water table in the well. Thus, the deionized water is mixed with inflows into the well and cross flows across the well, and may also exit at outflow points. This process generally reaches a steady state; the corresponding FEC profile in the well is known as the steady-state recirculation $\log$.

Ambient flow FEC logs or data. After recirculation stops, the inflows, outflows, and cross flows still occur, even without pumping (i.e., the well is shut in). These bring in water of salinity higher than deionized water, thus producing a series of FEC logs with peaks that grow with time. These are called ambient flow logs, acquired during ambient (no-pumping) flow conditions.

To expedite the analysis of FEC log data, a computer program called BORE II (Doughty and Tsang, 2000) has been developed that considers multiple inflow or outflow points along the wellbore during shut-in or pumping, including the case of horizontal flow across the wellbore. BORE II solves the one-dimensional advection-diffusion equation, assuming steady-state fluid flow, to calculate the evolution of fluid salinity, which is 
proportional to electrical conductivity, in a wellbore or wellbore section. BORE II compares model results to log data in a variety of ways (e.g., FEC as a function of depth for a series of times, or FEC as a function of time at a given depth). BORE II has an interactive, graphical user interface and runs on a personal computer under the Windows operating system. BORE II is a modification and extension of an older code called BORE (Hale and Tsang, 1988), which considered inflow points only and did not provide an interactive comparison to field data.

As an important side remark, the FEC logging method, while being a useful and efficient technique, has never been suggested as a stand-alone method, because of non-uniqueness of interpretation common to all well logging methods. A good combination, as is practiced by Nagra and elsewhere, is FEC logging followed by confirmatory doublepacker tests at a few specific intervals (as determined by the FEC logs) for direct measurements of local transmissivities and regional flow.

\subsection{Field Experiment and FEC Log Data}

Six FEC logging experiments were conducted at Borehole 24PB, from February 24-28, 2006, and will hereafter be referred to by the chronological order in which they occurred. The initial configuration, which was consistent for Tests 1 through 5, used a tremmie pipe set at 240 mbgs for injection of deionized water. For Test 6 the tremmie pipe was raised to $225.9 \mathrm{mbgs}$ to permit better delineation of shallower flowing intervals. Figure 4 shows a photograph of the FEC testing operation in progress in the field. For all tests, a well pump was set at the bottom of the casing, and the pump fluid was run through flow totalizers at the surface. During the recirculation phase of testing, the pumped fluid was routed through deionizing resin tanks and then reinjected through a tremmie pipe. During acquisition of flowing FEC logs, after the recirculation of deionized fluid in the borehole was halted, the pumped fluid was discharged through a flow totalizer (shown in Figure 4) into a surface impoundment. Periodic manual logging of the flow totalizer permitted determination of the pumping rate.

To summarize the testing conditions:

- Water table is at $122 \mathrm{~m}(400 \mathrm{ft})$.

- Casing ends at about $146 \mathrm{~m}$ (479 ft), it is not cemented in place.

- Pump is below water table at the bottom of the casing.

- Water deionizing equipment is just above ground surface.

- Depth of deionized water (DI) injection: Tests 1-5: $420 \mathrm{~m}$; Test 6: $225.86 \mathrm{~m}$.

- Salinity measurements below $0.027 \mathrm{~g} / \mathrm{L}$ are not observable, as they correspond to too high a resistivity value for the tool to measure. 


\subsubsection{Conversion of FEC to equivalent $\mathrm{NaCl}$ concentration}

Calibrated FEC logs for six tests are available for analysis (Table 1, Figure 5(a)-5(f)). Resistivity in the field is measured and converted to resistivity at $20^{\circ} \mathrm{C}$ using the Arps (1953) equation:

$r e s_{2}=\frac{T_{1}+21.5}{T_{2}+21.5} r e s_{1}$

To convert from resistivity at $20^{\circ} \mathrm{C}$ to equivalent $\mathrm{g} / \mathrm{L} \mathrm{NaCl}$ we use the following relationship:

$$
[N a C l](g / L)=\frac{5.4004}{\operatorname{Re} s(\Omega-m)}
$$

which is based on the equation: $F E C\left(20^{\circ} C\right)=1870 C-40 C^{2}$, developed by Hale and Tsang (1988), where FEC is in $\mu \mathrm{S} / \mathrm{cm}$ and $\mathrm{C}$ is in $\mathrm{g} / \mathrm{L}$.

\subsubsection{Constant flow-rate pump test}

Water levels measured manually during Test 5 are shown in Figure 6. Note that a drawdown of $0.2 \mathrm{~m}(0.7 \mathrm{ft})$ corresponds to a flow rate of $145 \mathrm{~L} / \mathrm{min}(38 \mathrm{gpm})$. Water levels were also monitored in Borehole NC-EWDP-24P, but no changes were observed. Using Dupuit's formula:

$$
h(r)-H=\frac{Q}{2 \pi T} \ln \frac{r}{R}
$$

where $h(r)-H$ is the observed head change within Borehole 24PB of radius $r=0.09 \mathrm{~m}$, and $R$ is the assumed location of no head change (arbitrarily chosen as $2 \mathrm{~m}$ ). The transmissivity, $T$, for $24 \mathrm{~PB}$ is calculated to be $6 \times 10^{-3} \mathrm{~m}^{2} / \mathrm{s}$. Since the FEC logs suggest little flow at depths below $320 \mathrm{mbgs}$, the total flowing length of the borehole is approximately $200 \mathrm{~m}$. This implies that the average borehole hydraulic conductivity is $3 \times 10^{-5} \mathrm{~m} / \mathrm{s}$, or a permeability of 3 darcies averaged over most of the Crater Flat tuff. Although the duration of pumping for this drawdown test was considered short to apply Dupuit's steady-state model, the purpose of this calculation was not to present a rigorous estimate for permeability, but to provide qualitative justification for our interpretation of 24PB as being highly permeable. 


\subsubsection{Additional open-borehole data}

Baseline temperature, formation salinity, and caliper logs are shown in Figure 7. These were collected soon after well development, and thus they may not represent undisturbed formation conditions. Comparing the temperature profile to the geothermal gradient suggests upflow of water in the wellbore above a depth of $300 \mathrm{~m}$, where temperature is nearly constant, and little flow below that depth, where the temperature profile follows the linear geothermal gradient.

Table 1. Fluid electrical conductivity experiments in chronological order

\begin{tabular}{|c|c|c|c|}
\hline Test $\#$ & $\begin{array}{c}\text { Recirculation } \\
\text { [gal/min] }\end{array}$ & Pumping [gal/min] & $\begin{array}{c}\text { Deionized Water } \\
\text { Injection Location } \\
{[\mathrm{mbgs}]}\end{array}$ \\
\hline 1 & 8.5 & 0.0 & 420 \\
\hline 2 & 8.3 & 3.0 & 420 \\
\hline 3 & 16.2 & 0.0 & 420 \\
\hline 4 & 16.5 & 10.5 & 420 \\
\hline 5 & 18.0 & 38.3 & 420 \\
\hline 6 & 16.1 & 0.0 & 225.9 \\
\hline
\end{tabular}

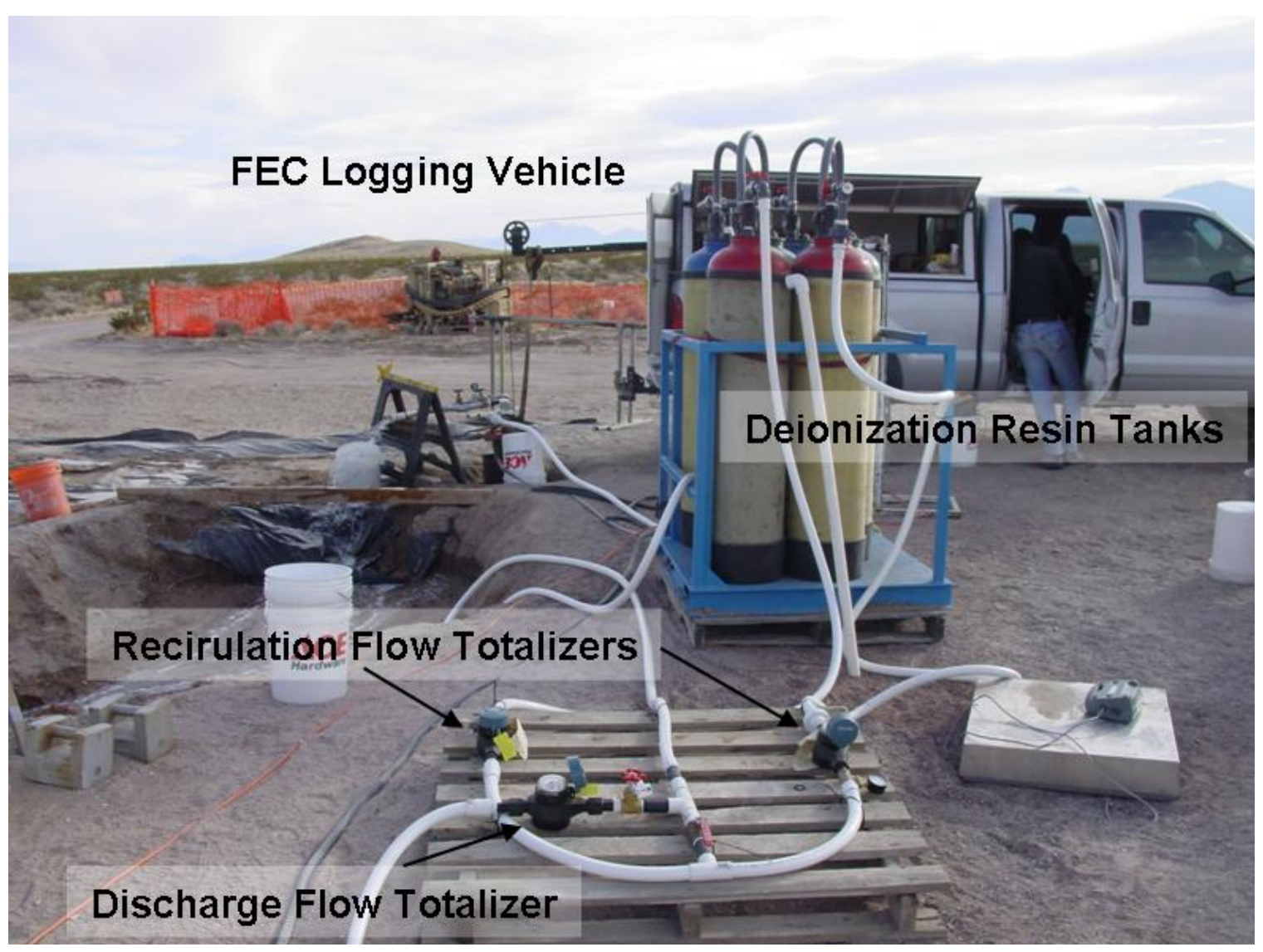

Figure 4. FEC logging equipment setup at Borehole NC-EWDP-24PB 


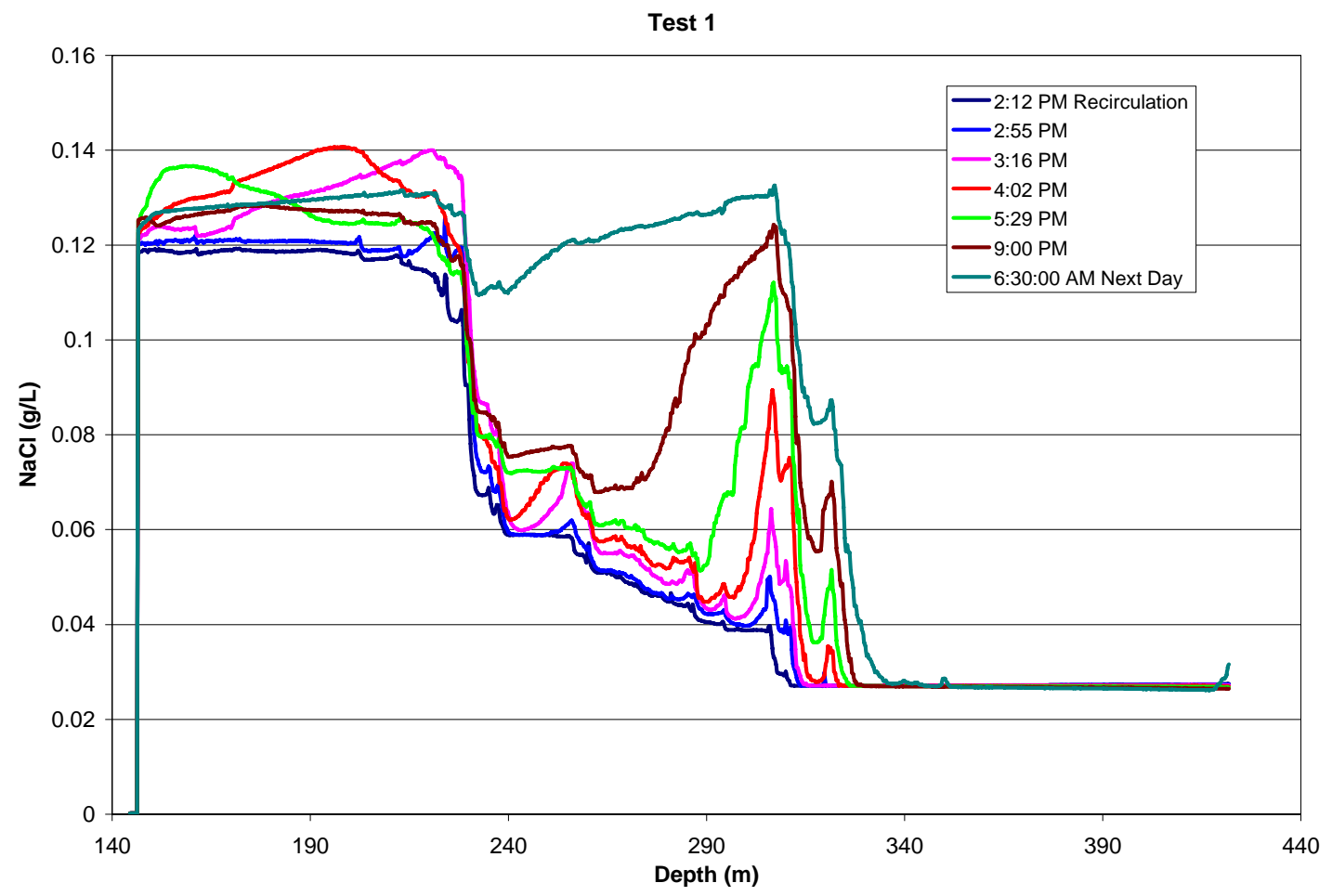

Figure 5(a). Test 1: Recirculation at 8 GPM (30.3 L/min) followed by ambient flow logging after 2:54 PM

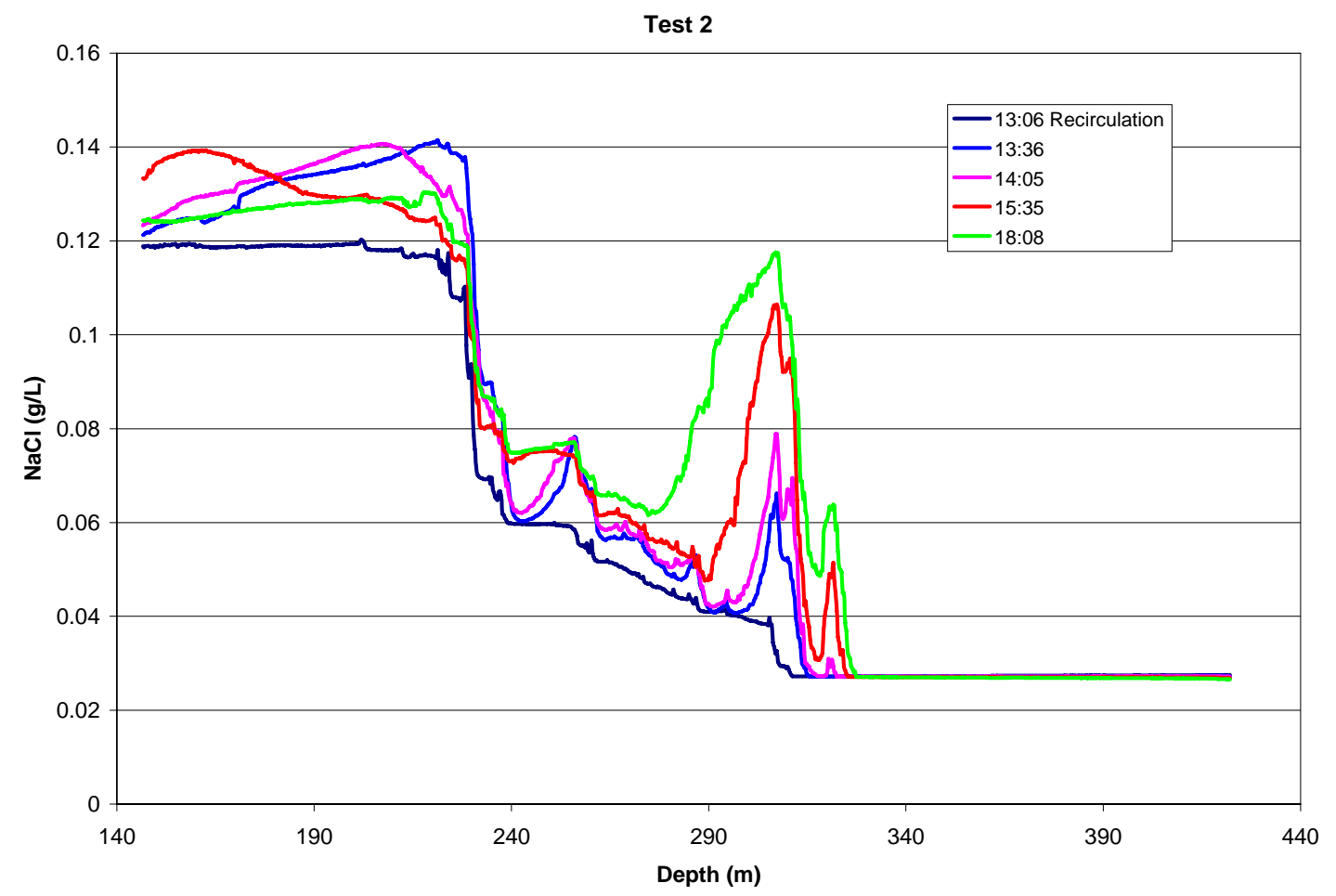

Figure 5(b) Test 2: Recirculation at 8.3 GPM (31.4 L/min) followed by pumping at 3 GPM (11.4 L/min) after 13:17 


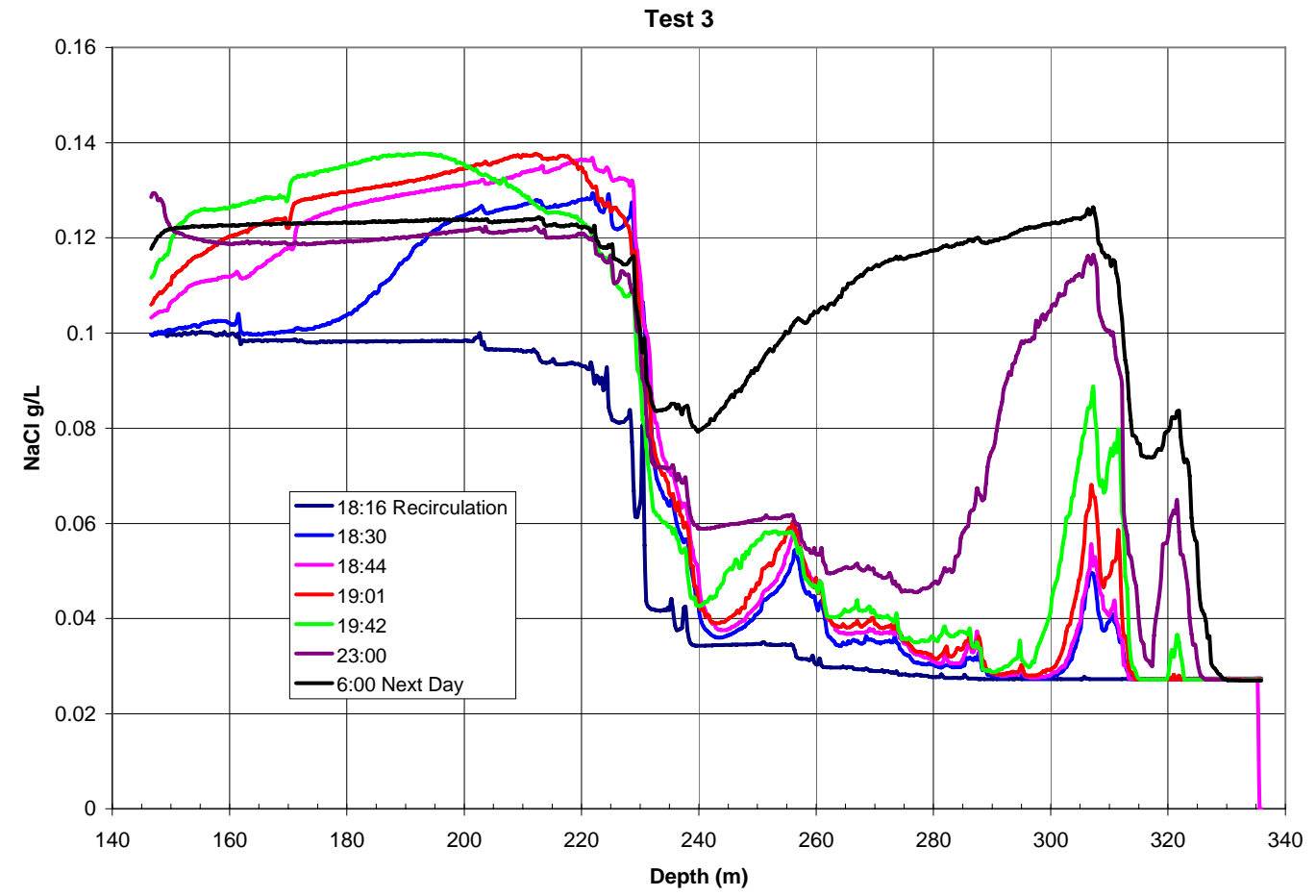

Figure 5(c). Test 3: Recirculation at 16.15 GPM $(61.1 \mathrm{~L} / \mathrm{min})$ followed by ambient flow logging after 18:24

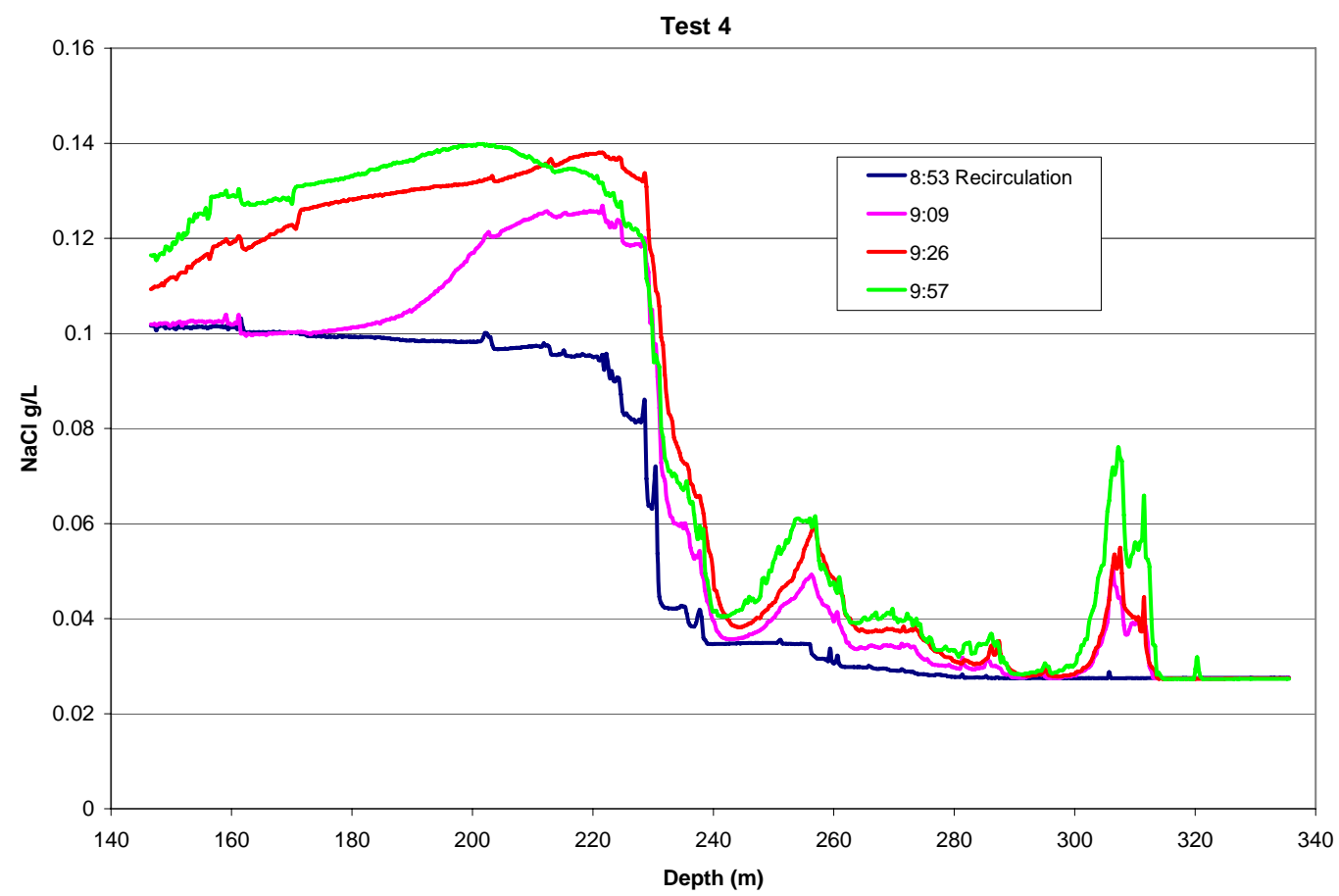

Figure 5(d). Test 4: Recirculation at $16.5 \mathrm{GPM}(62.4 \mathrm{~L} / \mathrm{min})$ followed by pumping at 10.5 GPM (39.7 L/min) after 9:05 


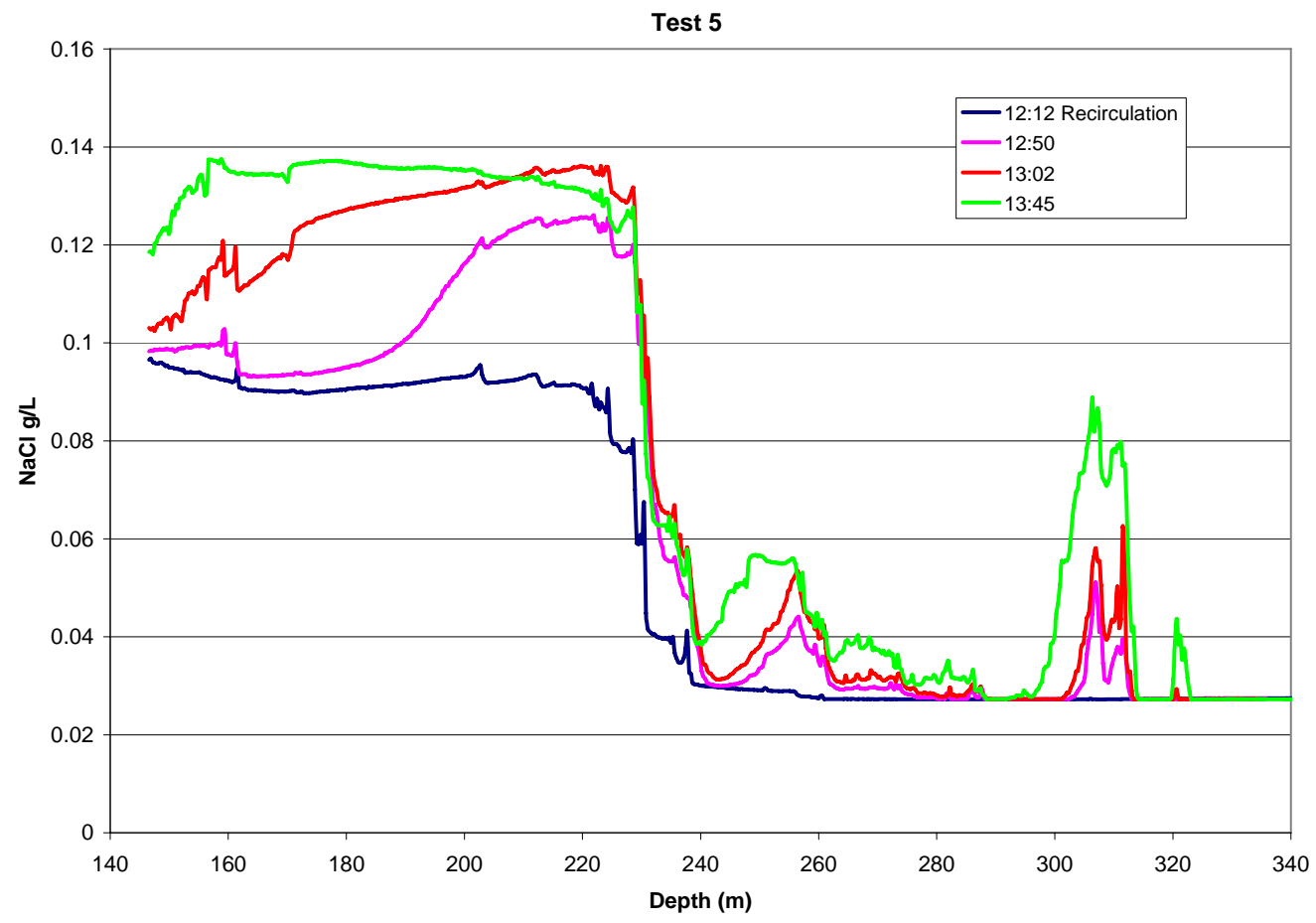

Figure 5(e). Test 5: Recirculation at $18 \mathrm{GPM}(68.13 \mathrm{~L} / \mathrm{min})$ followed by pumping at 38.3 GPM (133.5 L/min) after 12:45

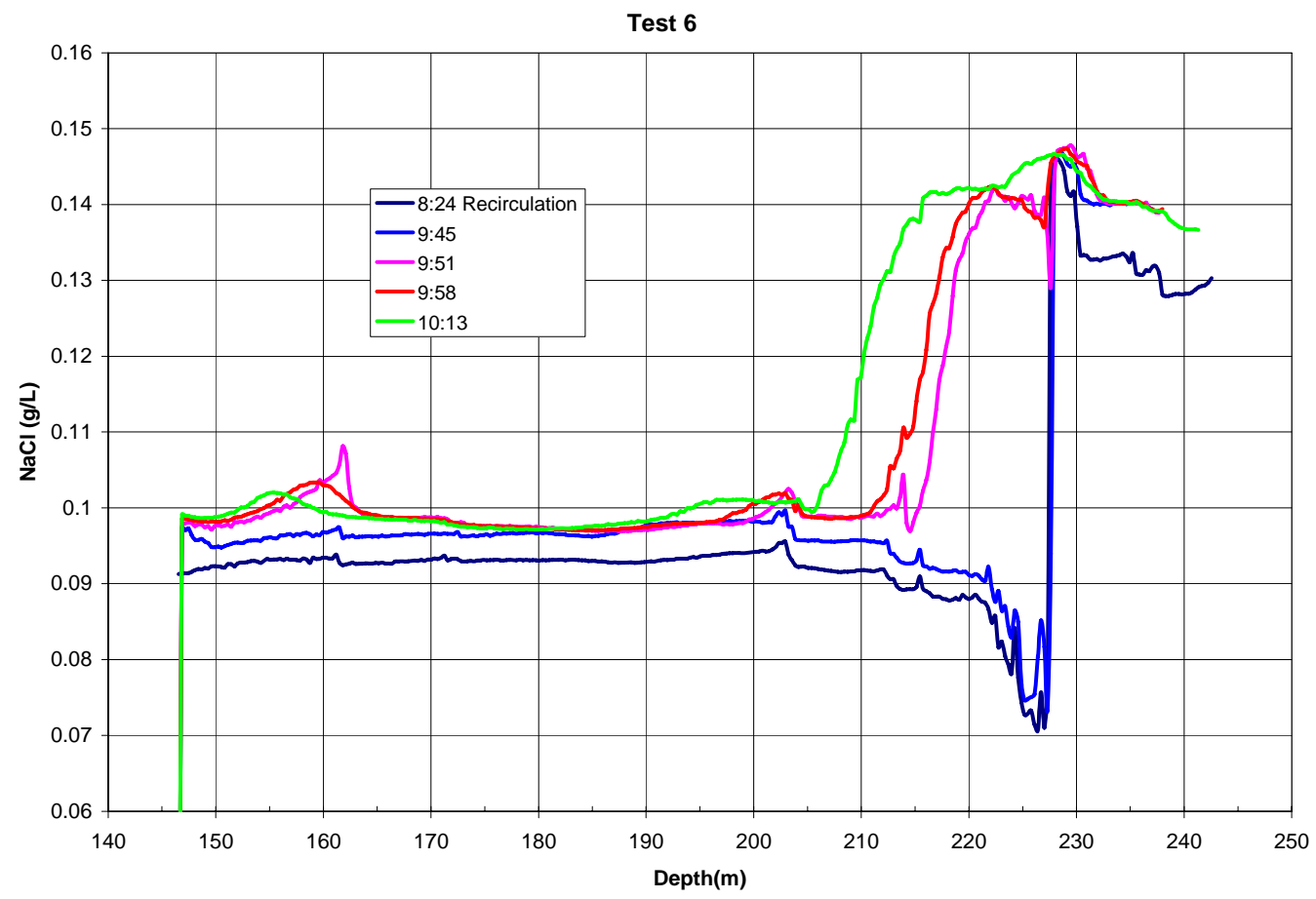

Figure 5(f). Test 6: Recirculation at 16.1 GPM (60.9 L/min) followed by ambient flow logging after 9:48 
Pump Test 39 GPM

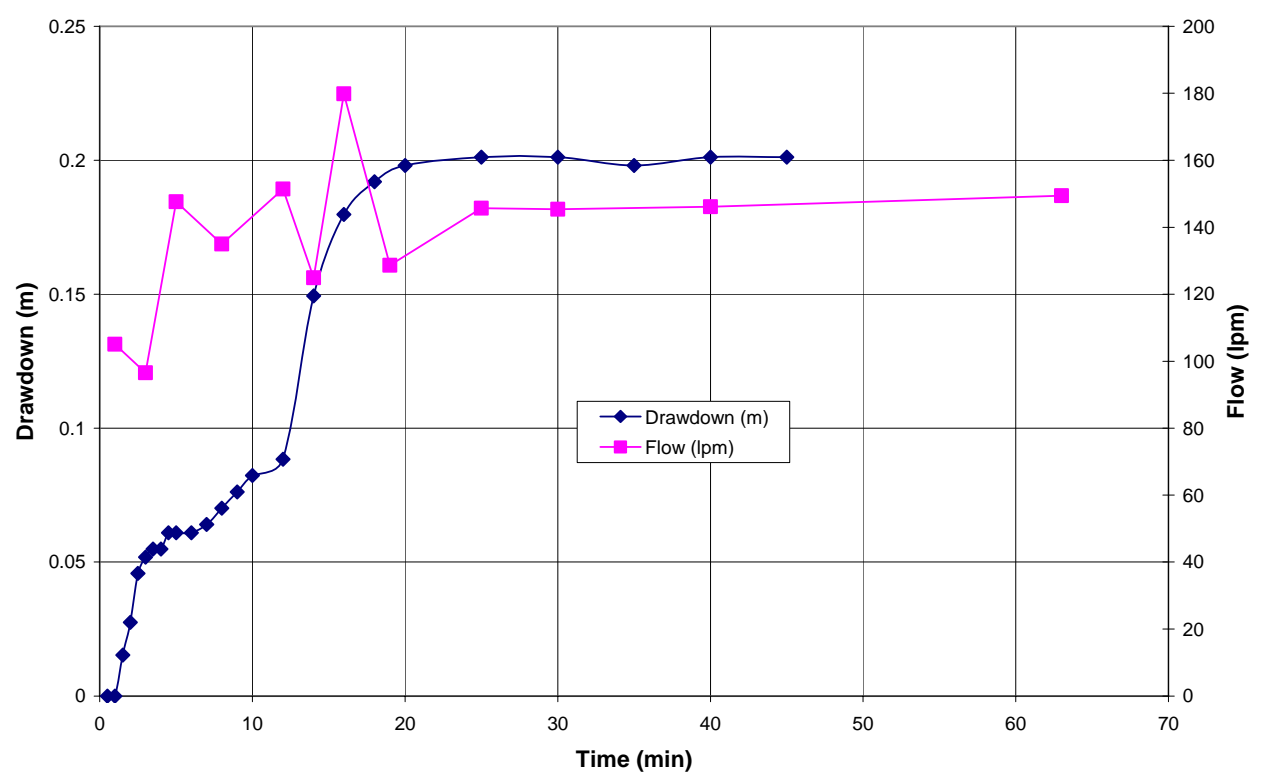

Figure 6. Water levels measured during FEC Test 5, pumping at 145 lpm. Crosswell measurements at $24 \mathrm{P}$ showed no response.

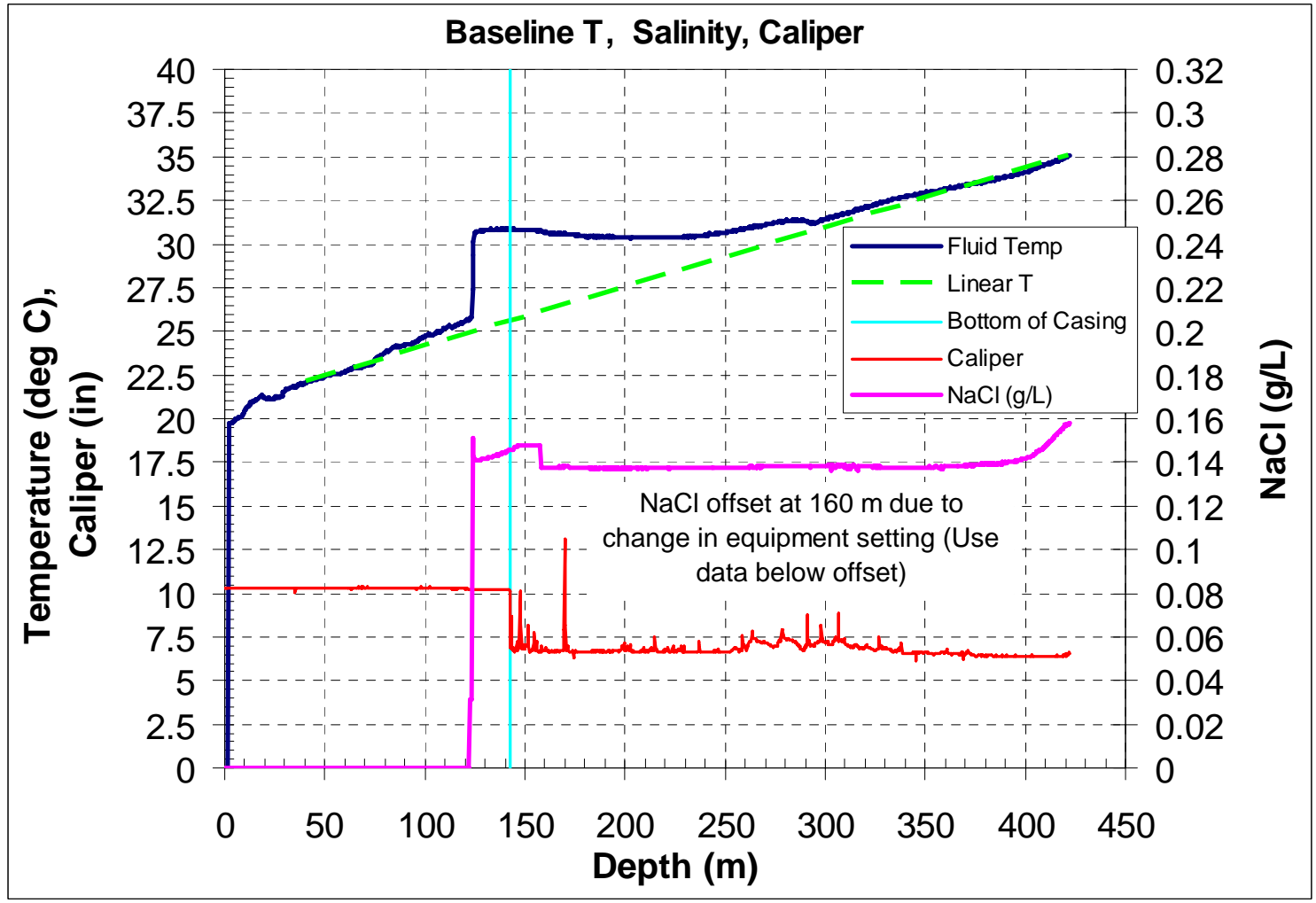

Figure 7. Baseline temperature, formation salinity, and caliper logs 


\section{Bore II Analysis}

\subsubsection{Assumptions}

BORE II models only the fluid flow and ion transport within the wellbore. Any processes occurring in the formation are only included by virtue of fluid sources and sinks (feed points) along the wellbore.

Basic assumptions are:

- Ion transport occurs by advection and diffusion along the wellbore.

- Steady-state flow field.

- Instantaneous mixing of feed-point fluid across a wellbore cross-section.

- One-dimensional model (along the borehole).

- Constant fluid density and viscosity.

- Constant wellbore diameter.

- FEC data corrected for temperature variation with depth.

Additional assumptions for the present analysis:

- Formation salinity is constant at $0.137 \mathrm{~g} / \mathrm{L}$.

- The DI injection at $420 \mathrm{~m}$ is at the bottom of the borehole, i.e. no downward flow below $420 \mathrm{~m}$.

\subsubsection{Approach}

We decided in this initial analysis to first match the ambient flow logs (Test 1, Test 3 , and Test 6) which are indicative of internal and cross flows from various points in the borehole. They are simpler in the sense that no pumping or recirculation is being conducted. Then the results will be used to calculate the FEC profile during recirculation and compare with steady-state recirculation data.

\subsection{Test 1 ambient flow analysis}

Test 1 FEC logs show that some peaks do not grow linearly with time (e.g., see Figure 5a at depths of 235 and $230 \mathrm{~m}$ ), suggesting that there is some transient behavior starting at the end of the recirculation period (at 2:54 pm), and extending about 20 minutes into the ambient flow period. (Note also that the time to reach steady-state conditions during the pump test is also about 20 minutes.) After about 20 minutes, all peaks appear to grow linearly with time. Therefore, the ambient flow analysis is conducted using the $3: 16 \mathrm{pm}$ profile (collected 22 minutes after recirculation ended) as an initial condition, and attempting to match later profiles (Section 3.3.3.1). Subsequently, the calibrated model will be compared to all profiles (Section 3.3.3.2). 


\subsubsection{Calibration of Test 1 Model}

The fitting was done by first identifying feed-point locations from peaks in the FEC logs, then considering the peaks one by one, starting with the bottom-most peak in the borehole (the most upstream feed point) and working upward, adjusting feed-point flow rate until the modeled FEC peak matches the observed FEC peak. Peaks are represented by a combination of inflow and outflow feed points. Ultimately, we used 56 points and accomplished a reasonable fit to the four profiles collected after 3:16 pm, as shown in Figure 8. The data are shown as dashed lines and the BORE II results as solid lines. The four times are 4:02 pm, 5:29 pm, 9:00 pm, and 6:30 am the next morning. This match is considered reasonably good: although not every peak is perfectly matched, the general trends shown in the data are reproduced by the model.

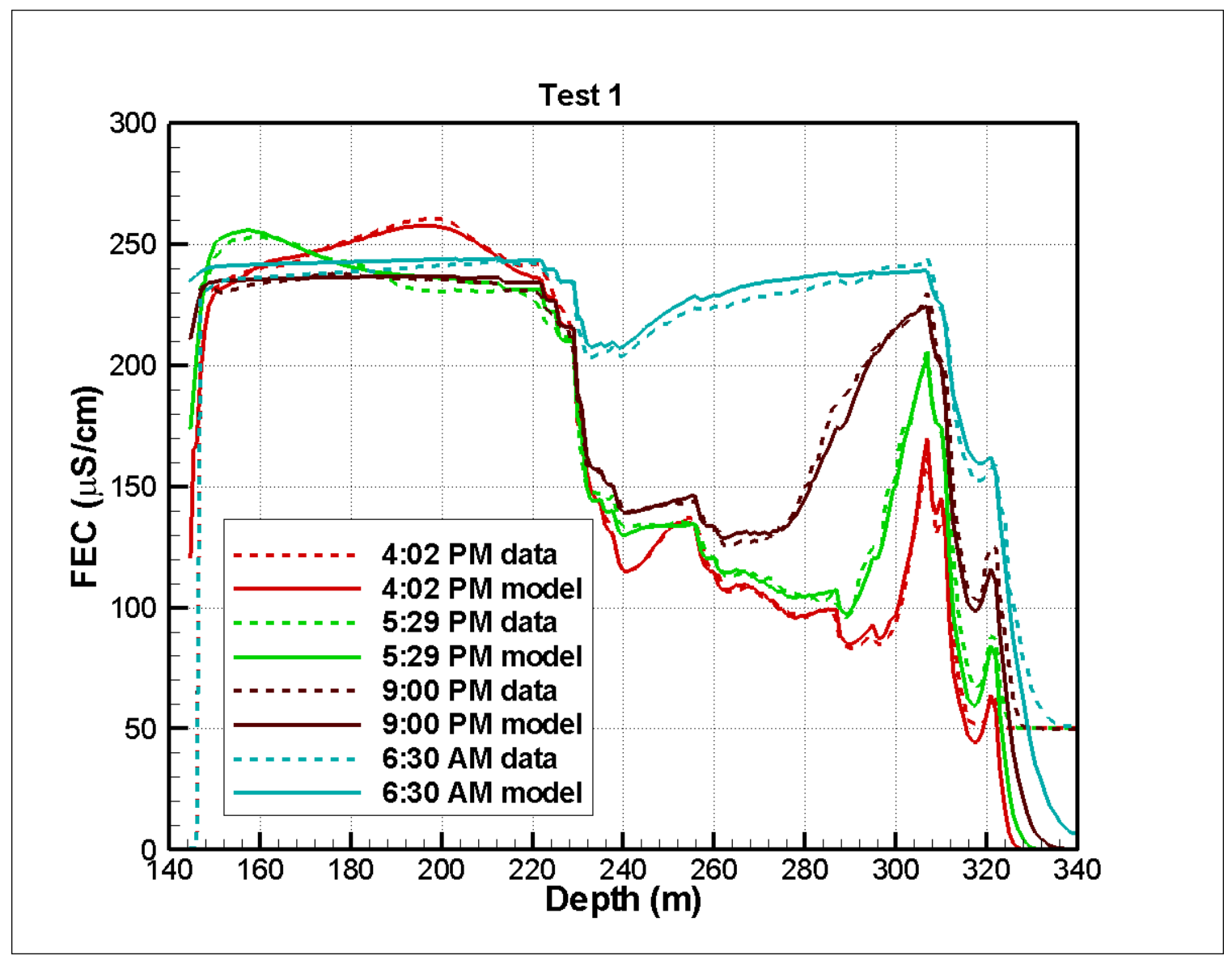

Figure 8. Data and model for Test 1 (ambient flow after recirculation at 8 GPM). Recirculation ends at 2:54 pm. Model uses 3:16 pm data as an initial condition. 
The model itself (the locations and strengths of 56 feed points) is given in Table 2 and presented graphically in Figure 9.

Table 2. Feed-point depth and strength for model developed from Test 1

\begin{tabular}{|c|c|}
\hline Depth (m) & $\begin{array}{l}\text { Feed Point Strength } \\
\text { (L/min) }\end{array}$ \\
\hline 322 & 0.13 \\
\hline 322 & -0.03 \\
\hline 321 & 0.12 \\
\hline 321 & -0.03 \\
\hline 315 & 0.03 \\
\hline 311 & 0.30 \\
\hline 311 & -0.09 \\
\hline 310 & 0.35 \\
\hline 310 & -0.10 \\
\hline 307 & 0.80 \\
\hline 307 & -0.22 \\
\hline 303 & 0.05 \\
\hline 299 & 0.05 \\
\hline 295 & 0.13 \\
\hline 295 & 0.00 \\
\hline 287 & 0.18 \\
\hline 287 & 0.00 \\
\hline 285 & 0.02 \\
\hline 285 & -0.01 \\
\hline 283 & 0.02 \\
\hline 283 & -0.01 \\
\hline 281 & 0.02 \\
\hline 281 & -0.01 \\
\hline 279 & 0.02 \\
\hline 279 & -0.01 \\
\hline 277 & 0.02 \\
\hline 277 & -0.01 \\
\hline 275 & 0.05 \\
\hline 275 & 0.00 \\
\hline
\end{tabular}

\begin{tabular}{|cc|}
\hline Depth (m) & $\begin{array}{c}\text { Feed Point Strength } \\
\text { (L/min) }\end{array}$ \\
273 & 0.05 \\
273 & 0.00 \\
271 & 0.05 \\
271 & 0.00 \\
269 & 0.05 \\
269 & 0.00 \\
267 & 0.05 \\
267 & 0.00 \\
265 & 0.03 \\
265 & 0.00 \\
260 & 0.13 \\
256 & 0.30 \\
238 & 0.30 \\
235 & 0.20 \\
231 & 1.00 \\
231 & -0.50 \\
229 & 3.00 \\
229 & -1.00 \\
225 & 2.00 \\
225 & -0.50 \\
222 & 2.50 \\
213 & 1.00 \\
203 & 0.50 \\
203 & 0.00 \\
162 & -4.90 \\
150 & -5.00 \\
145 & -1.00 \\
\hline
\end{tabular}




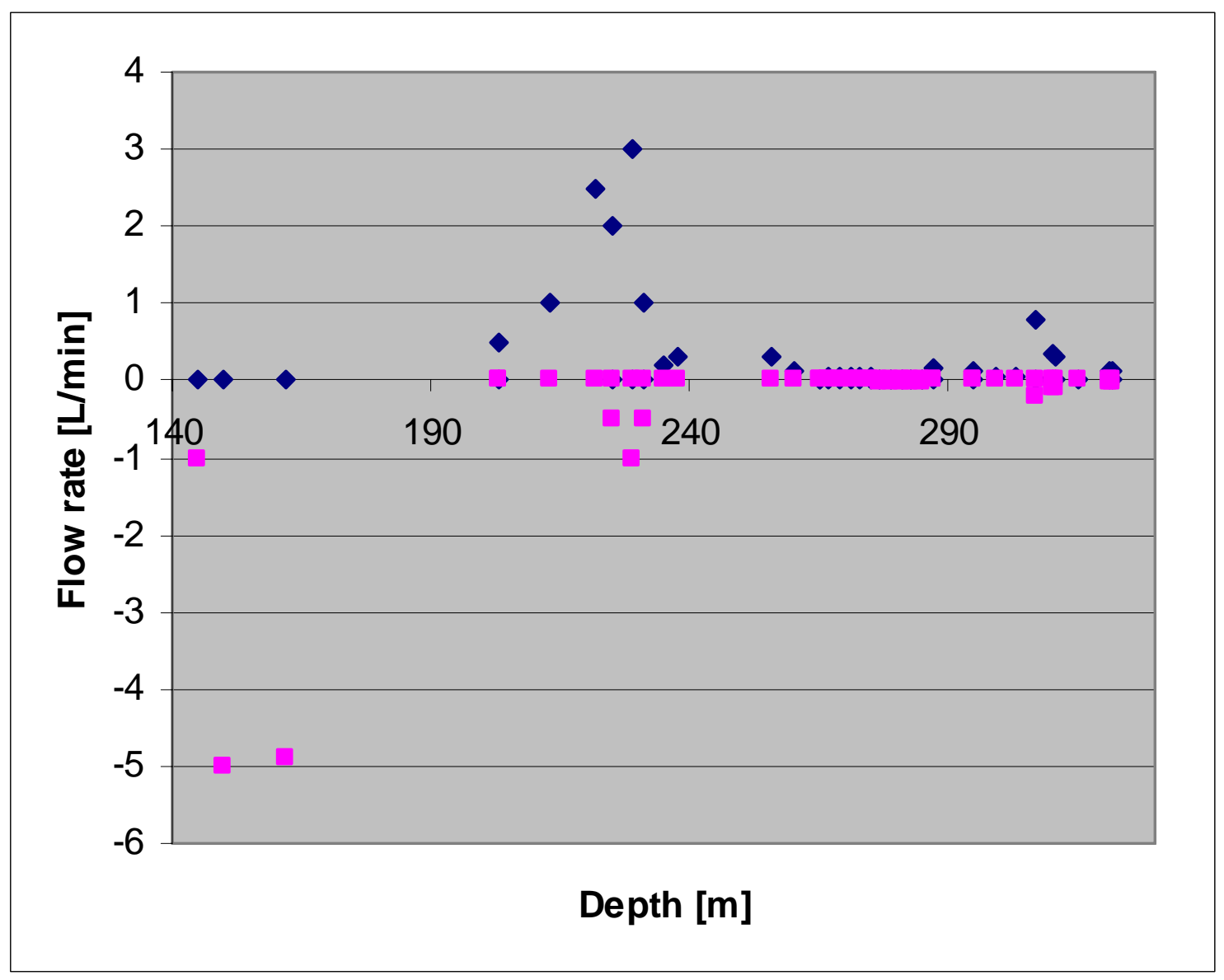

Figure 9. Feed-point strengths for the model based on Test 1. Inflow points are shown in blue and outflow points are shown in pink.

Note that some feed points have positive strength (inflow to the borehole) and some are negative (outflow from the borehole). This means that they have higher or lower, respectively, far-field pressure heads compared with the average borehole shut-in pressure. Where positive and negative feed points exist at the same depth, it indicates that fluid is flowing past the borehole (denoted cross flow, representing possible regional flow across the borehole). Over most of the borehole logged interval, the model shows a combination of upflow and crossflow, which is evidenced by an unbalanced inflow and outflow at a given depth, with the inflow greater than the outflow. Assuming complete mixing between inflow and wellbore fluid at a given depth with inflow $q_{\text {in }}$ and outflow $q_{\text {out }}$ yields upflow $q_{u}$ given by

$q_{u}=q_{\text {in }}-q_{\text {out }}$

and crossflow $q_{c}$ given by

$q_{c}=\left(q_{\text {in }}+q_{\text {out }}\right) / 2$. 
Just below a depth of $230 \mathrm{~m}$, the upflow is about $3 \mathrm{~L} / \mathrm{min}(=3.5 \mathrm{~L} / \mathrm{min}$ inflow -0.5 $\mathrm{L} / \mathrm{min}$ outflow), with cross flow from the bottom of the well to this point totaling about 2 $\mathrm{L} / \mathrm{min}(=(3.5 \mathrm{~L} / \mathrm{min}$ inflow $+0.5 \mathrm{~L} / \mathrm{min}$ outflow $) / 2)$. Between 230 and $200 \mathrm{~m}$ depths, the upflow is about $11 \mathrm{~L} / \mathrm{min}(=3 \mathrm{~L} / \mathrm{min}$ from below $+10 \mathrm{~L} / \mathrm{min}$ inflow $-2 \mathrm{~L} / \mathrm{min}$ outflow $)$, with about $6 \mathrm{~L} / \mathrm{min}(=(10 \mathrm{~L} / \mathrm{min}$ inflow $+2 \mathrm{~L} / \mathrm{min}$ outflow $) / 2)$ cross flow. Between $200 \mathrm{~m}$ and the bottom of the casing at about $145 \mathrm{~m}$, there is outflow at $11 \mathrm{~L} / \mathrm{min}$, resulting in a no-flow condition at the top of the wellbore. These overall flows are shown graphically in Figure 10.

Cross flow may be converted to transport velocity with

$v_{t}=q_{c} /(2 L D \phi)$

where $L$ is the thickness of the zone through which cross flow occurs, $D$ is the borehole diameter, the factor of two is derived from potential theory to account for the convergence of flow lines toward a borehole, and $\phi$ is porosity. Taking $L=30 \mathrm{~m}$ for the upper zone $(200-230 \mathrm{~m})$ and $L=90 \mathrm{~m}$ for the lower zone $(230 \mathrm{~m}-320 \mathrm{~m}), D=0.17 \mathrm{~m}$, and $\phi=0.01$ (considered to be at the upper bound of accepted values for the welded Bullfrog Tuff) converts $q_{c}=6 \mathrm{~L} / \mathrm{min}$ to $v_{t}=31 \mathrm{~km} / \mathrm{yr}$ for the upper zone and $q_{c}=2 \mathrm{~L} / \mathrm{min}$ to $v_{t}=3.4 \mathrm{~km} / \mathrm{yr}$ for the lower zone.

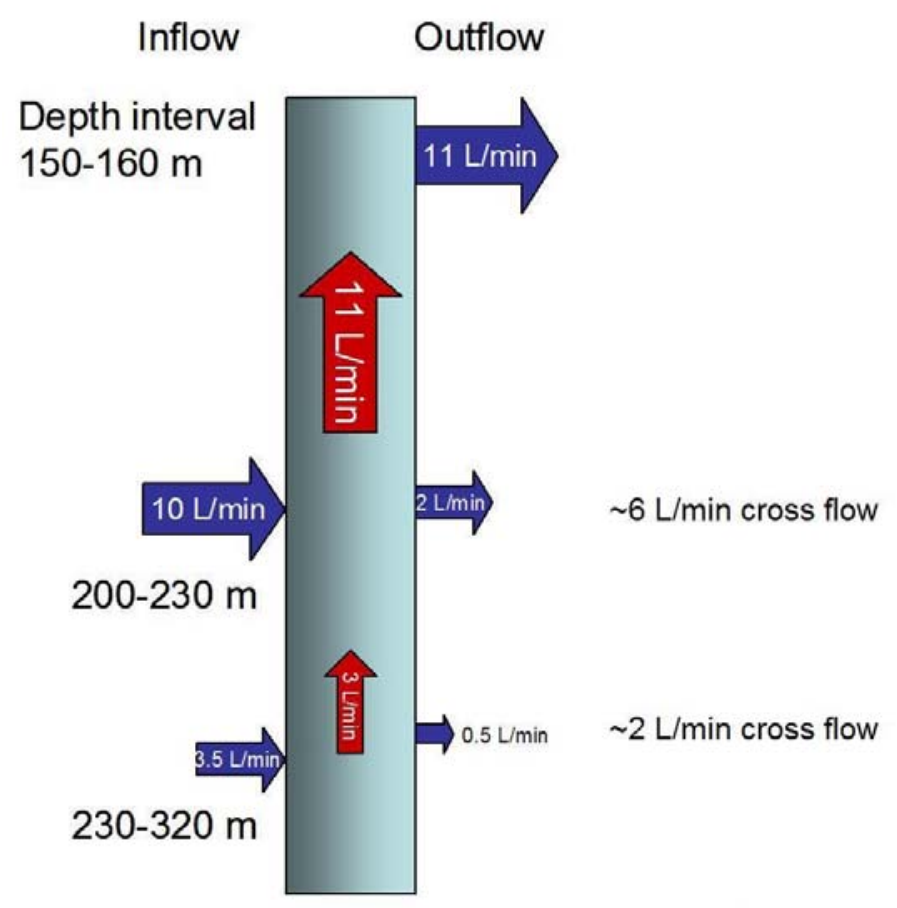

Figure 10. Overall pattern of inflow and outflow for the model based on Test 1 


\subsubsection{Comparison to all Test 1 Profiles}

To check how well the results apply to all the Test 1 logs, the model derived in the previous section is used to model the Test 1 ambient flow period using the steady-state recirculation profile as an initial condition. The results are shown in Figure 11. The six profile times are 2:55 pm, 3:16 pm, 4:02 pm, 5:29 pm, 9:00 pm, and 6:30 am the next morning. The late-time profiles are as well-matched as before. The mismatches to the early-time profiles (within the hypothesized 20-minute transient period) indicate that the model under-predicts peak growth above a depth of about $290 \mathrm{~m}$.

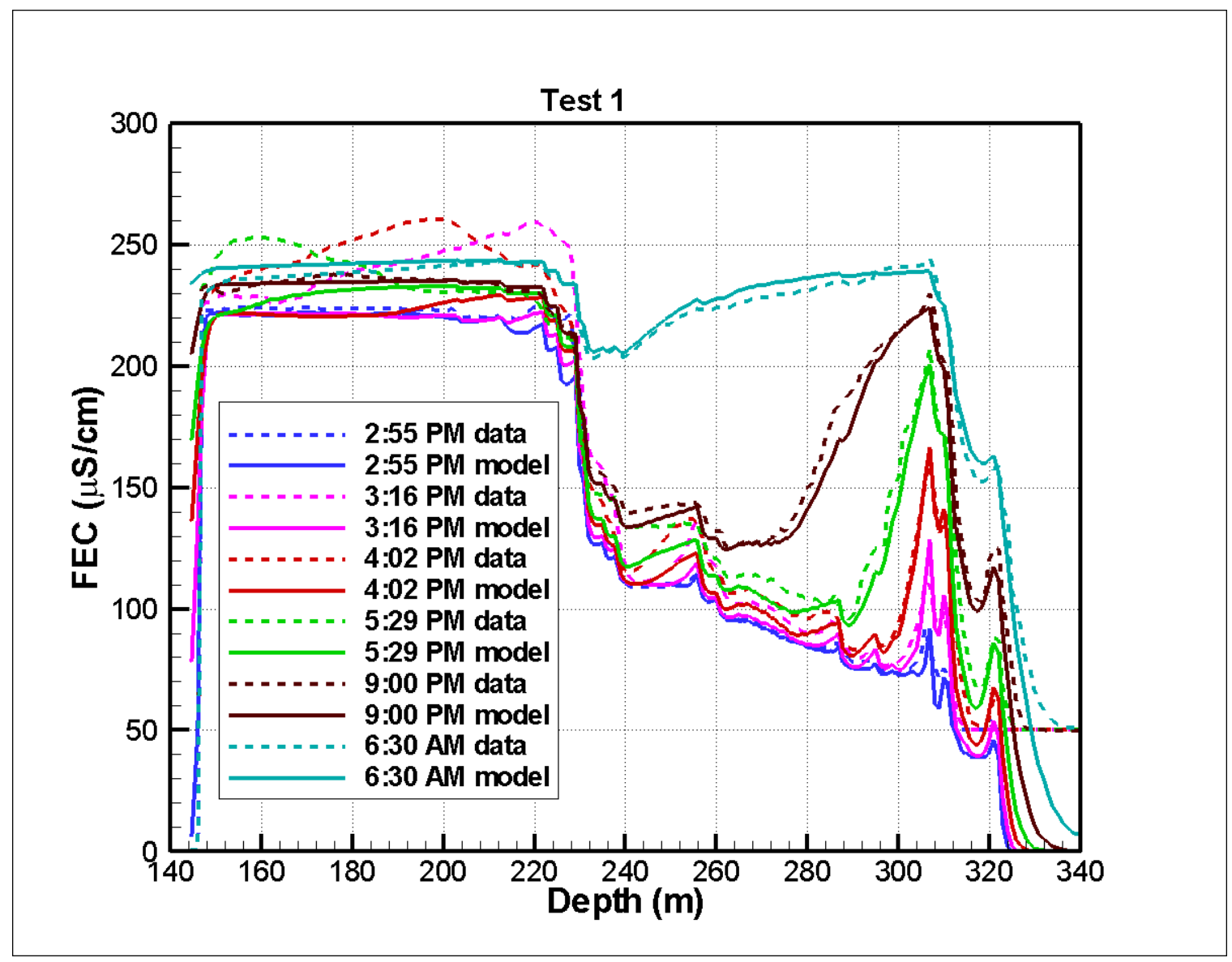

Figure 11. Data and model for Test 1 (ambient flow after recirculation at 8 GPM). Recirculation ends at 2:54 pm. Model uses steady-state recirculation data as an initial condition. 


\subsection{Test 1 recirculation analysis}

\subsubsection{Ambient Flow Model Prediction of Steady-State Recirculation Profile}

The model developed for the ambient flow period (Section 3.3.3) was used to predict the steady-state recirculation profile, by including recirculation flow. This is done by adding a feed point at the bottom of the borehole to represent the injection of DI water. The resulting FEC profiles for the model and the data are shown in Figure 12. The model FEC values (red), while reproducing the trend and detailed structures of the curve, greatly underpredict the field FEC values (black), suggesting that in the model not as much formation fluid is entering the wellbore during the recirculation period as the field data indicates. This finding is consistent with the model under-prediction of peak growth during the 20-minute transient period at the start of Test 1 (Figure 11).

\subsubsection{Variation of Feed-Point Strengths to Match Steady-State Recirculation Profiles}

As a first attempt to adjust the ambient flow model to match the steady-state recirculation profile, we use two simple algorithms to artificially increase the inflow of formation water by adjusting feed-point strengths of the ambient flow model. In one case, inflow and outflow point strengths both increase together and in the other case as inflow point strength increases outflow point strength decreases. Neither method is expected to accurately reproduce the dynamics that occur as wellbore pressure changes, which can be rather complicated if various feed-points have different far-field heads (see Tsang and Doughty, 2003), but they may provide useful end members of a spectrum of behavior. Both methods produce very good matches to the steady-state recirculation profiles, as shown for the first method in Figure 13. However, they predict different upflows out the top of the logged interval. Specifically, when both inflow and outflow strengths increase, upflow at the top of the logged interval is equal to the flow at the top of the borehole - the recirculation rate. However, when outflow points decrease as inflow points increase, a large upflow results at the top of the logged interval. This may or may not be physical. 


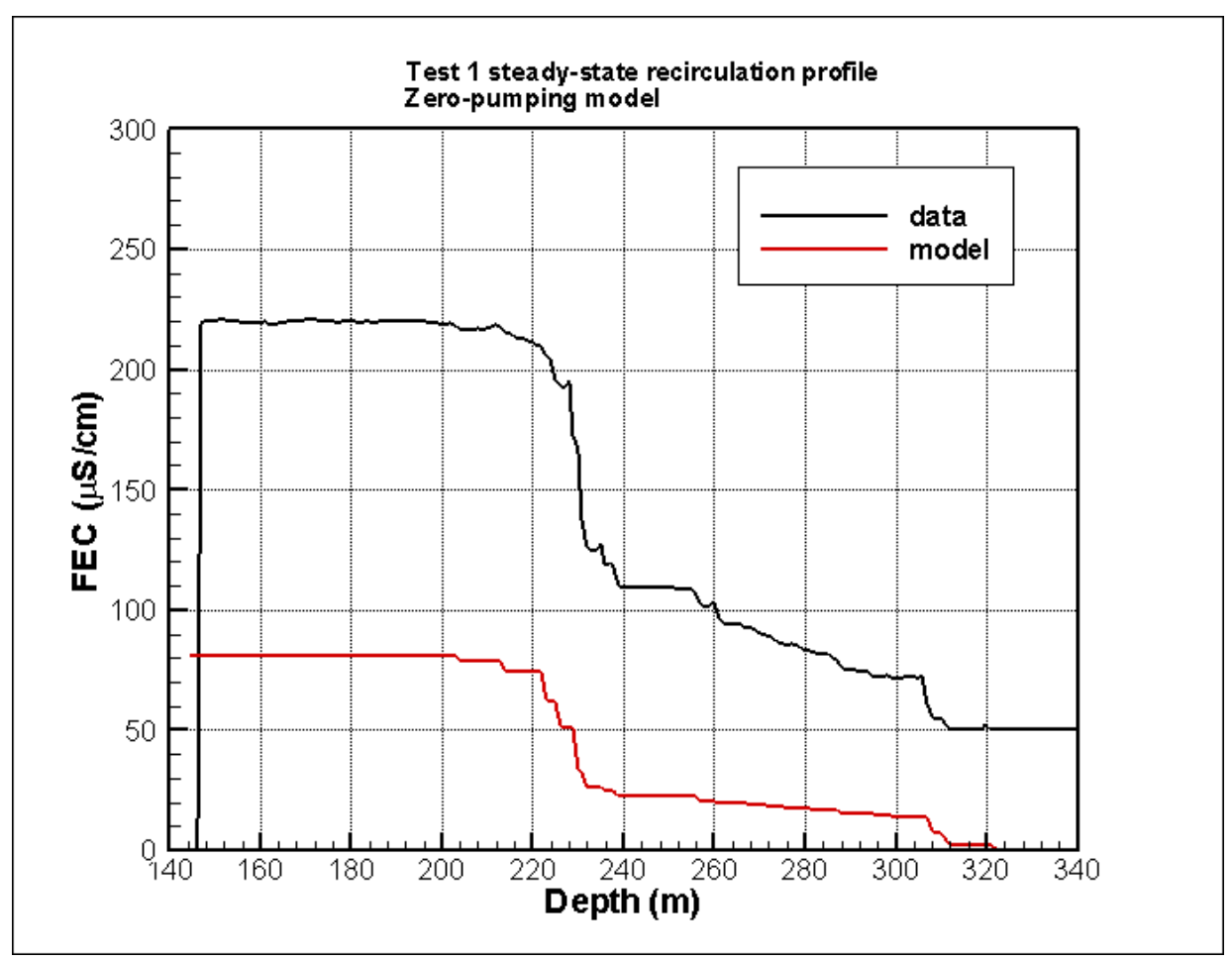

Figure 12. Data and model for Test 1 steady-state recirculation profile. The model is developed from the Test 1 ambient flow data.

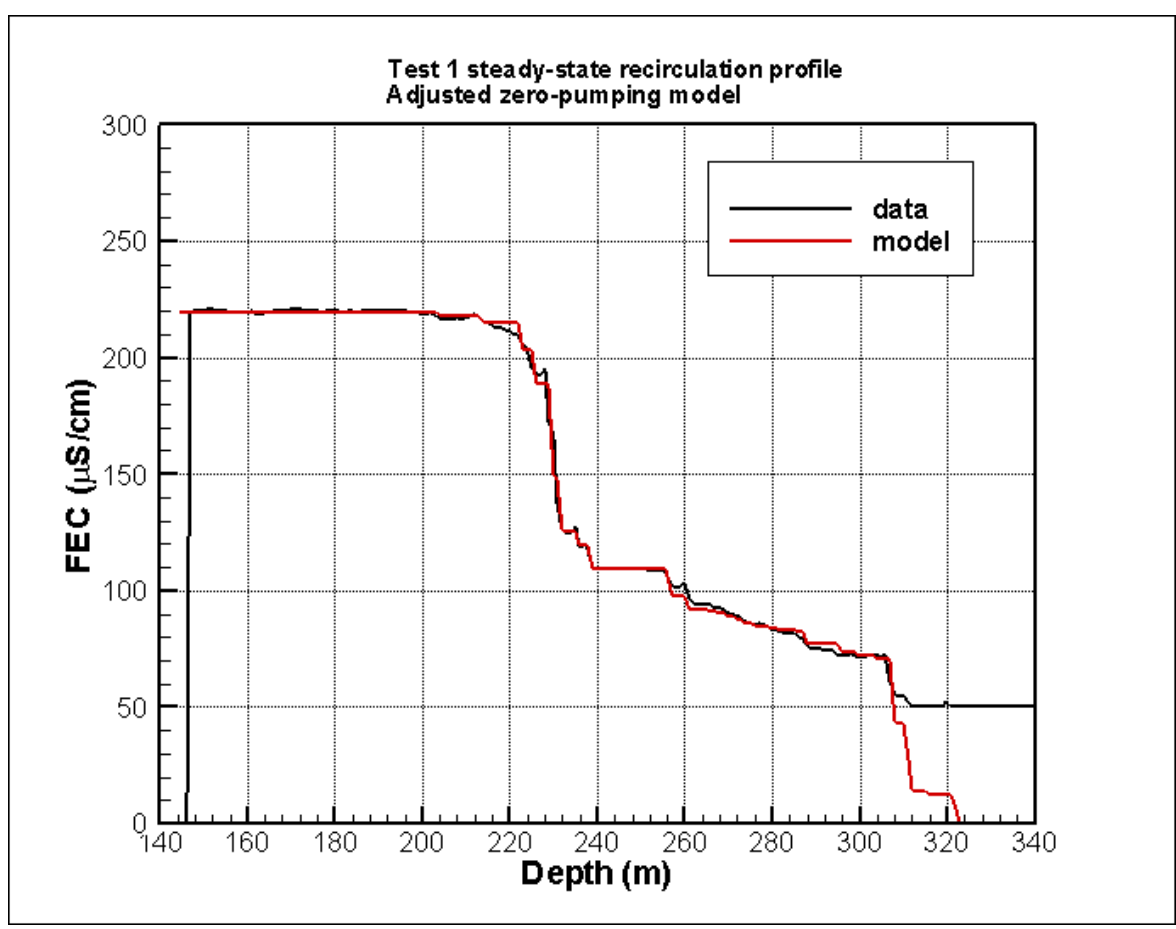

Figure 12. Data and model for Test 1 steady-state recirculation profile. The model is developed from the Test 1 ambient flow data, then adjusted by increasing feedpoint strengths until recirculation data is matched. 
Table 3 shows the adjustment factors (multiplicative factors for inflow points) that are obtained. For Test 1, for both methods, the adjustment factors are similar: about 4-8 for all inflow/outflow points at depths below $260 \mathrm{~m}$ and 9-12 at shallower depths. These adjustments reflect the amount of inconsistency that exists between the recirculation data and the ambient flow data.

We find that with the artificial adjustment factors, our model feed point strengths are roughly comparable to estimates of inflow made for the recirculation period using the following simple mixing model applied to the Test 6 recirculation data (Figure 5f). At a depth of 225-227 mbgs, for the formation salinity of $0.14 \mathrm{~g} / \mathrm{L}$ to be reduced to the observed value of $0.07 \mathrm{~g} / \mathrm{L}$ when de-ionized water with salinity essentially 0 is added at a rate of $16 \mathrm{GPM}$, inflow from the formation must also be about $16 \mathrm{GPM}$, or $61 \mathrm{~L} / \mathrm{min}$. While the DTPS data shown in the next section leads us to believe that the ambient flow condition analysis, with its order of magnitude smaller inflow rates, better represents undisturbed conditions, at this point we do not have a sound physical basis for explaining recirculation-log results.

Table 3. Artifical Adjustment Factors Needed to Reconcile Ambient Flow Model with Recirculation Conditions.

\begin{tabular}{|l|c|c|c|c|c|}
\hline Test & $\mathrm{z}<290 \mathrm{~m}$ & $290 \leq \mathrm{z}<261 \mathrm{~m}$ & $261 \leq \mathrm{z}<230 \mathrm{~m}$ & $230 \leq \mathrm{z}<200 \mathrm{~m}$ & $200 \leq \mathrm{z}<140 \mathrm{~m}$ \\
\hline $\begin{array}{l}1 \text { (inflow and } \\
\text { outflow increase) }\end{array}$ & 6.5 & 6.5 & 12 & 12 & 12 \\
\hline $\begin{array}{l}1 \text { (inflow } \\
\text { increases and } \\
\text { outflow } \\
\text { decreases) }\end{array}$ & 4 & 8 & 9 & 12 & $\mathrm{n} / \mathrm{a}$ \\
\hline $\begin{array}{l}3 \text { (inflow and } \\
\text { outflow increase) }\end{array}$ & 8 & 3 & 7 & 11 & 11 \\
\hline $\begin{array}{l}6 \text { (inflow and } \\
\text { outflow increase } \\
\text { at all depths) }\end{array}$ & 6 & 6 & 10 & 14 & 14 \\
\hline $\begin{array}{l}6 \text { (inflow and } \\
\text { outflow increase } \\
\text { above DI injection } \\
\text { depth) }\end{array}$ & 1 & 1 & 1 & 17 & 17 \\
\hline
\end{tabular}

\subsubsection{Comparison to other ambient flow tests: Test 3 and Test 6}

Analysis of Tests 3 and 6 is very preliminary. So far, we find that using the model developed during the ambient flow period of Test 1 produces a reasonable match to the ambient flow period of Test 3, as shown in Figure 14, in which the 18:44 profile (collected about 20 minutes after recirculation ends) is used as an initial condition.

Similar to the Test 1 analysis, if the steady-state recirculation profile is used as an initial condition, early-time peaks are underpredicted by the model, whereas late-time profiles are matched reasonably well by the model, as shown in Figure 15. Also, the artificial adjustment factors needed for the ambient flow model to match the Test 3 recirculation 
profiles (Table 3) are similar to those required for Test 1. Thus, overall, the Test 3 results are consistent with the Test 1 analysis results.

For Test 6, all the ambient flow profiles were obtained within the first 20-minute period when transient effects complicate the FEC profiles. Thus we do not expect the Test 1 model to reproduce Test 6 well, and it does not.

The artificial adjustments needed for feed-point strength to reproduce the Test 6 recirculation profile (Table 3 ) are not too different from those needed for Tests 1 and 3. For Test 6, the adjustment is done in two ways: in the first approach, all feed-point strengths are adjusted, whereas in the second approach, only feed points above the DI injection point are adjusted. The results for the two methods are not strikingly different, but show that when more flow is coming up from below (the first approach), the DI water is diluted more, and hence smaller shallow inflow is required to match the observed FEC profile. Table 3 summarizes all the adjustments for the different tests.

\subsection{Discussion of FEC Data}

The inconsistency between the interpretation of the recirculation data with the analysis results of the ambient flow data is of concern. At this point, we do not know which analysis better reflects reality, but it is obvious that the ambient period, when no pumping occurs, is more stable than during recirculation, when slight fluctuations in flow rates and pressure may have a significant impact. Recall that in the pumping test, $0.2 \mathrm{~m}$ of pressure head change corresponds to a flow rate from the formation of $145 \mathrm{~L} / \mathrm{min}$. Thus small uncontrolled, unmeasurable pressure changes may strongly impact inflow and outflow.

Note that the FEC analysis method was not originally designed to treat either recirculation data or ambient data, but a post-recirculation period during which the well is being pumped. Several data sets exist for these conditions (Tests 2, 4, and 5), and we anticipate that analyzing them will help clarify the interpretation of the FEC data. 


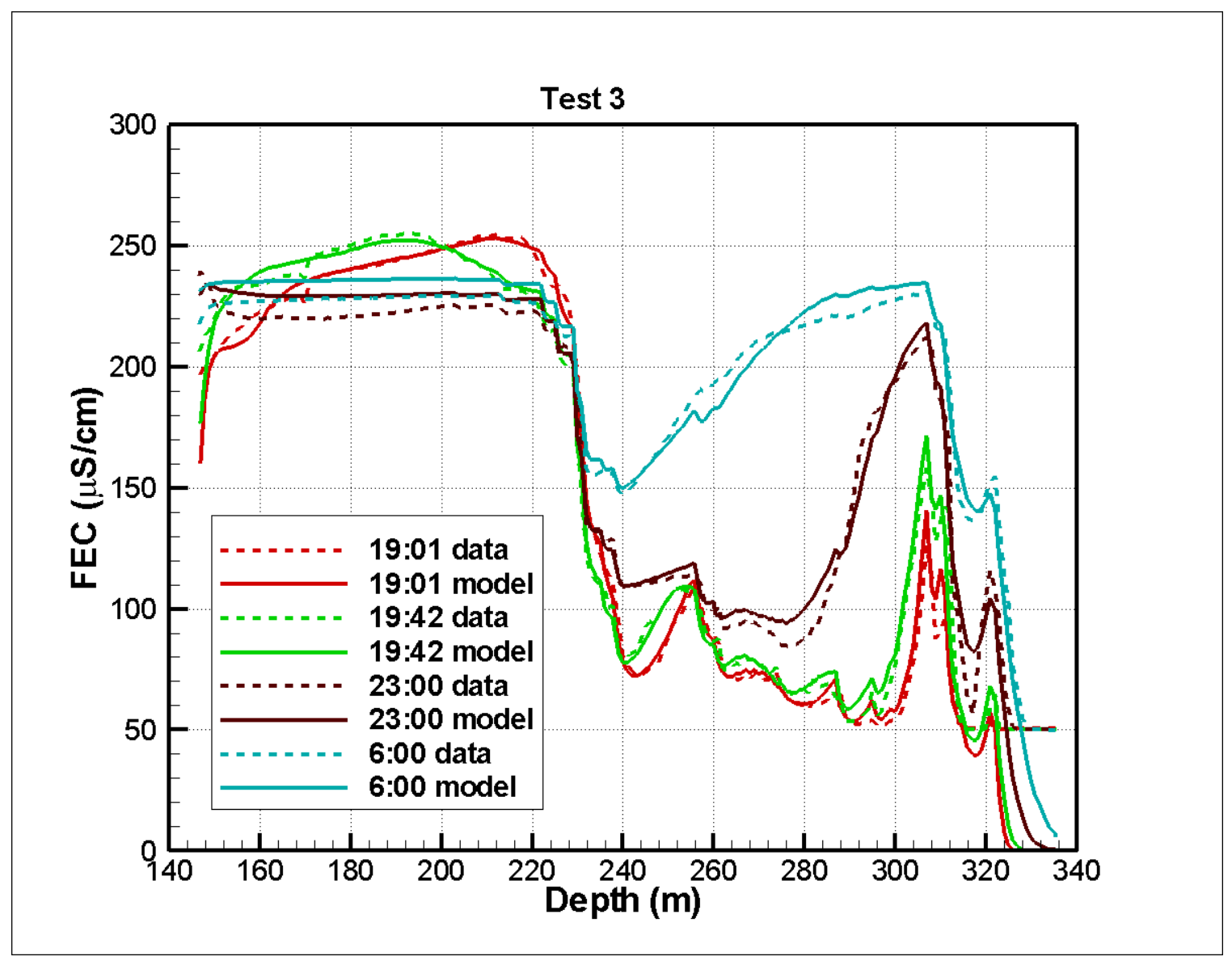

Figure 14. Data and model for Test 3 (ambient logging following recirculation at 16 GPM). Recirculation ends at 18:24. Model uses 18:44 data as an initial condition. 


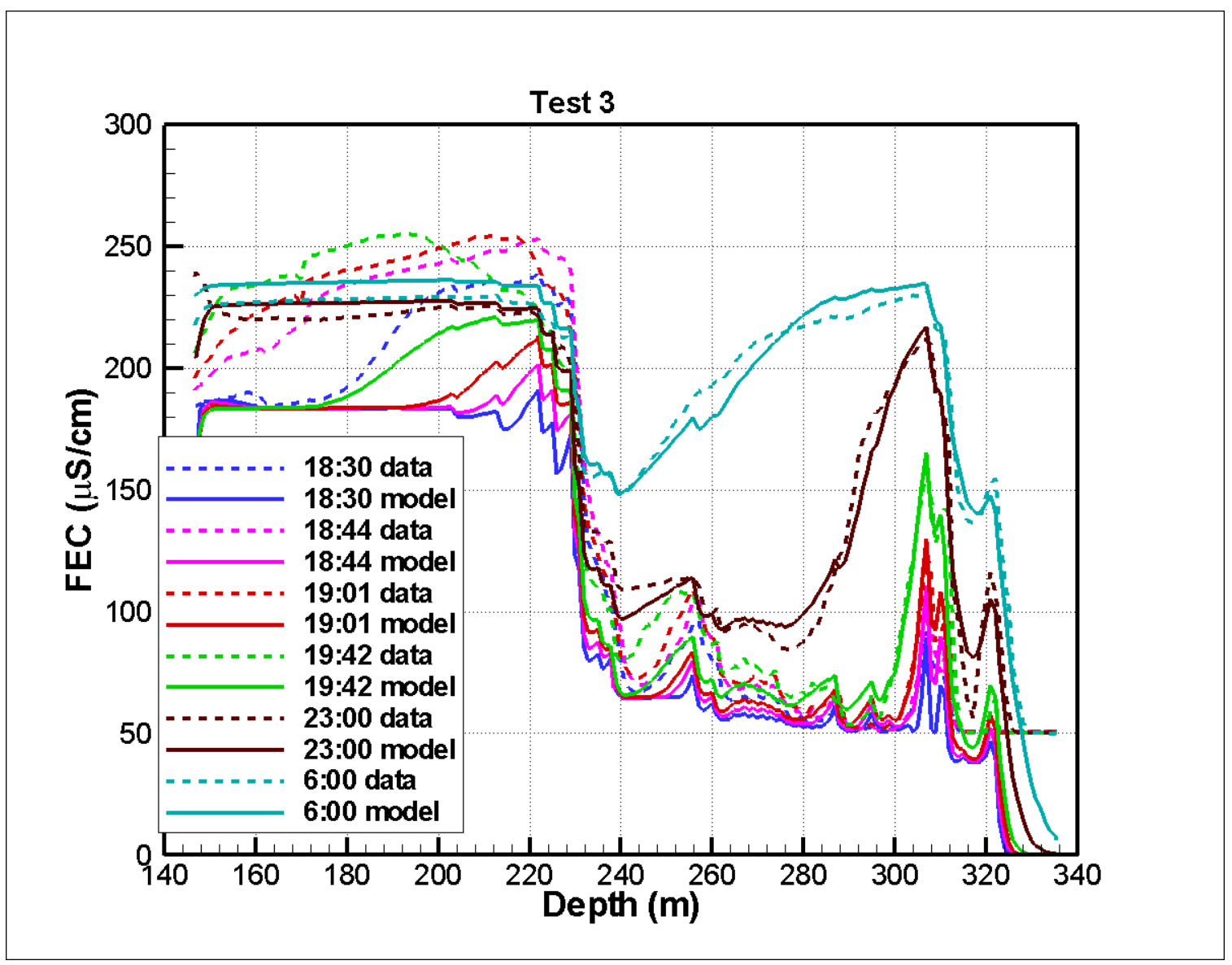

Figure 15. Data and model for Test 3 (ambient logging following recirculation at 16 GPM). Recirculation ends at 18:24. Model uses steady-state recirculation data as an initial condition.

\section{Thermal Measurements in Borehole NC-EWDP-24PB}

\subsection{History of Thermal Logging Techniques}

Borehole temperature logs have been used to interpret hydrologic conditions within groundwater, geothermal and petroleum reservoirs. Borehole temperature logs were used by Bredehoeft and Papadopulos (1965) to estimate vertical fluxes in groundwater due to recharge. Others attempted to determine regions of horizontal water flow, using both conventional wire-line and optical-fiber temperature logging techniques (Safanda et al., 2005; Förster et al., 1996). However, open well logs are subject to the effects of intraborehole flow. As pointed out by Förster et al. (1996), even in the case of a backfilled well in thermal equilibrium, an independent determination of formation thermal properties is required to separate out heat conduction from the effects of heat convection caused by fluid advection. Drury and Lewis (1983) and Drury (1984) used very precise temperature measurements to investigate fracture flow in granitic formations, using deviations in temperature logs to determine regional heat flow. Jessop 
(1987) interpreted temperature logs acquired years after $413,000 \mathrm{~m}^{3}$ of brine were injected in a disposal well near the City of Regina, Saskatchewan, Canada, to estimate lateral flow rates.

Several specialized instruments for measuring thermal profiles and estimating horizontal fluid velocity have been developed. The In Situ Permeable Flow Sensor (Ballard, 1996; Su et al., 2006), estimates both the direction and magnitude of fluid flow using temperature transients measured on the surface of a buried, uniformly heated cylinder. The TERO sensor, developed by the Geological Survey of Finland for investigating borehole thermal properties (Kukkonen et al., 2005), is a temperature measurement device operated by a wireline within a borehole. However, logging an entire wellbore using the $1.5 \mathrm{~m}$ long TERO sensor would be a time consuming process.

\subsection{Thermal Logging in Borehole NC-EWDP-24PB}

In Borehole 24PB, the DTPS, essentially a borehole-length hot-wire anemometer, was used to measure temperatures as the basis to estimate fluid flux. The DTPS consists of two components: (1) a distributed temperature sensor (DTS), and (2) a constant linear heat source. To perform a DTPS measurement, heat is applied uniformly along the length of a borehole with the total power monitored at the surface. The DTS is then used to record the thermal profile as a function of time and depth down the borehole. Taking into account natural variations in thermal properties, regions of the wellbore subject to lateral fluid flow are identified as relatively cooler zones on the DTS logs as heating progresses.

The continuous heater in 24PB consists of two-conductor direct burial 14 gage tray cable (TC). To form a complete circuit the buried end of the TC was soldered together and protected by electrical insulating resin. During wellbore completion, the TC was strapped to the outside of the center piezometer tube using stainless bandclamps, which also served to attach the U-tube groundwater samplers. To operate the heater, $240 \mathrm{~V}$ singlephase power was supplied in the field using a portable generator. A power meter (E-mon D-mon Series 1000 by Hunt Power) was used to continuously monitor the rate of borehole heating. Since the $412 \mathrm{~m}$ long heater has a resistance of $6.8 \Omega$, using Ohm's Law the total power supplied to the heater $(240 \mathrm{~V} \times 35.3 \mathrm{~A})$ is $8470 \mathrm{~W}$, or $20.6 \mathrm{~W} / \mathrm{m}$. The temperature sensor consisted of a 50/125 $\mu \mathrm{m}$ multimode indoor/outdoor rated fiberoptic cable lowered down the center of the 24PB piezometer to a total depth of $358 \mathrm{mbgs}$. Temperature logging was performed using a Sentinel DTS-SR supplied by Sensornet Ltd.

Heating of Borehole 24PB started at 18:22 on May 16, 2006, and temperature logging was halted May 17, 2006, at 19:52 (25.5 hours later) after the fiber-optic cable was damaged by wildlife. Because of the damage to the cable, a post-test calibration was not performed. Although temperature logs were acquired at 15-minute intervals throughout the experiment, Figure 16 (for clarity) shows only a subset of the 102 acquired temperature logs. The initial three logs shown were acquired at 15 -minute intervals. The fourth log shown was acquired 45 minutes after the third log, and all subsequent logs were acquired at one-hour intervals. The large increases in temperature that were 
observed down to a depth of 75 meters are attributed to 24PB's large-diameter (14-inch) dual casing completion. Post-completion density logging (personal communication, unqualified density log performed by Raymond Federwisch) reveals large reductions in density of the sand/bentonite back-fill material between $21 \mathrm{mbgs}$ and $76 \mathrm{mbgs}$. This reduced density would manifest itself in reduced thermal conductivity, resulting in the observed increased temperatures within this depth range during heating. Figure 17 shows the final DTPS temperature log acquired 25.5 hours after the start of heating, plotted along with the final FEC log acquired during FEC Test 5. Seven zones of reduced temperatures which correlate with FEC flow zones, have been assigned alphabetical identifiers in Figure 17.

\subsection{Estimates of Fluid Flux Using 24PB Thermal Data}

Figure 18 shows the temperature difference between the final heating log and the initial baseline log. To estimate fluid flux rate using the Borehole 24PB temperature data, we assume that the difference between the measured temperature data and a purely conductive temperature (i.e., no convective heat removal by flowing water) is attributable to fluid removing heat from the system. This assumes that the difference in the measured temperature from the baseline temperature value, referred to hereafter as $\Delta T_{\text {measured }}$, and the hypothetical "conduction-only" temperature difference from the baseline value, $\Delta T_{\text {conductive, }}$ is proportional to fluid flow. The hatched region in Figure 18 encompasses a range of temperature profiles for $\Delta T_{\text {conductive, where the upper bound represents the }}$ assumption that formation thermal properties are constant. The lower bound is based on the assumption that differences in heating are caused by either variations in formation thermal properties or more regional heat transport processes. As such, the local maxima in measured temperatures are assumed to occur at "no-flow" regions of the borehole. Based upon the data collected to date and the assumptions of $\Delta \mathrm{T}$ used in our simple model, further efforts to refine the range of assumed values are not warranted.

Recommendations will be made at the end of the report as to how to eliminate some of the uncertainties in these assumptions by collecting additional data sets in 24PB using the DTPS.

For each identified flow zone, the rate of heat removal by natural fluid advection is calculated to be:

$$
E=\left(1-\frac{\Delta T_{\text {measured }}}{\Delta T_{\text {conductive }}}\right) Q L
$$

where the rate of heating, $Q(20.5 \mathrm{~W} / \mathrm{m})$, the average temperature increase, $\Delta T_{\text {measured }}$, and the length of the zone, $L$, are known. The values for the expected, purely conductive temperature in the absence of fluid flow, $\Delta T_{\text {conductive, }}$ are assumed based upon either the upper or lower bound (top or bottom of the hatched polygon) shown in Figure 18. To convert the heat removal rate to volumetric fluid flux, $F$, we divide $E$ by the amount of heat removed by advected fluid: 


$$
F=\frac{E}{C_{p, \text { water }} \Delta T_{\text {measured }}}
$$

Table 4 shows estimated fluid fluxes for the seven identified flow zones, with upper and lower bounds for $\Delta T_{\text {conductive. }}$ Each zone has been assigned an alphabetical identifier from A through $\mathrm{G}$. The upper limit of the hatched region, corresponding to $\Delta T_{\text {conductive }}=$ $4.46^{\circ} \mathrm{C}$, assumes the formation has homogeneous thermal properties, where all variation in $\Delta T_{\text {measured }}$ is attributed to fluid flux. The lower limit of the hatched region assumes that thermal properties are variable, and each flow zone has its vertical extent designated by end points, where by assumption no flow occurs. The end points are reflected by local maxima in $\Delta T_{\text {measured }}$ Zone $\mathrm{A}^{*}$ (from $229 \mathrm{mbgs}$ to $231 \mathrm{bmgs}$ ) is a subsection of Zone $\mathrm{A}$,.

To check the reasonableness of the assumed upper limit for $\Delta T_{\text {conductive }}\left(4.46^{\circ} \mathrm{C}\right)$ an analytic solution for radial conduction of heat from a linear source into an infinite isotropic thermal media was used to model heat flux into the Bullfrog tuff. The temperature as a function of radius, $r$, from the linear heater and time, $t$, is:

$$
\Delta T(r, t)=-\frac{Q}{4 \pi \alpha} E i\left(-\frac{r^{2}}{4 D t}\right) .
$$

We assume the thermal properties of the welded Bullfrog formation as specified in "Thermal Conductivity of Non-Repository Lithostratigraphic Layers," MDL-NBS-GS000006 REV 01, October 2004, with a rock bulk density of $\rho=2260 \mathrm{~kg} / \mathrm{m}^{3}$, a rock specific heat of $C_{p}$, rock $=985 \mathrm{~J} / \mathrm{kg}^{\circ} \mathrm{C}$, a formation matrix porosity of $\phi=0.12$, and a wet thermal conductivity of $\alpha=1.81 \mathrm{~W} / \mathrm{m}^{\circ} \mathrm{C}$. Given a density and specific heat capacity of water of $\rho_{w}=1000 \mathrm{~kg} / \mathrm{m}^{3}$ and $C_{p \text {,water }}=4190 \mathrm{~J} / \mathrm{kg}^{\circ} \mathrm{C}$, respectively, we obtain a volumetric heat capacity of the rock-water system of $C_{p \text {, (rock }+ \text { water })}=2.73 \times 10^{6} \mathrm{~J} / \mathrm{m}^{30} \mathrm{C}$. Using the radius of the piezometer, $(r=0.025 \mathrm{~m})$ as the distance between the heater and the fiberoptic temperature sensor, the temperature change after 1500 minutes of heating is calculated to be $4.81^{\circ} \mathrm{C}$. Figure 19 compares the radial heating model using the assumed Bullfrog formation parameters to the DTPS data acquired at $261 \mathrm{mbgs}$ depth. To demonstrate the sensitivity of the measured temperatures to the distance between the heater and sensor, Figure 19 also shows the solution to the radial heating model using $r=0.031 \mathrm{~m}$, which provides a better "fit" to the acquired data. While the Borehole 24PB DTPS data cannot uniquely determine the separation between the heater and the sensor, $r$, the assumption used for all calculations in this report, $r=0.031 \mathrm{~m}$, is considered reasonable. 
Table 4. Estimates of Thermal Flux, Groundwater Flux, and Transport Velocity using DTPS Measurements.

\begin{tabular}{|c|c|c|c|c|c|c|c|}
\hline \multirow[b]{2}{*}{ Zone } & \multirow[t]{2}{*}{$\begin{array}{l}\text { I, Length } \\
\text { (m) }\end{array}$} & \multicolumn{2}{|c|}{$E$, Heat Flux (J/s) } & \multicolumn{2}{|c|}{$\begin{array}{l}F \text {, Estimated Flux } \\
\text { (L/min) }\end{array}$} & \multicolumn{2}{|c|}{$v$, Transport velocity (m/yr) } \\
\hline & & $\begin{array}{l}\mathrm{T}_{\text {ideal }} \\
\text { constant }\end{array}$ & $\begin{array}{l}\mathrm{T}_{\text {ideal }} \\
\text { variable }\end{array}$ & $\begin{array}{l}\mathrm{T}_{\text {ideal }} \\
\text { constant }\end{array}$ & $\begin{array}{l}\mathrm{T}_{\text {ideal }} \\
\text { variable }\end{array}$ & $\begin{array}{l}\mathrm{T}_{\text {ideal }} \text { constant } \\
\phi_{\mathrm{f}}=0.01\end{array}$ & $\begin{array}{l}T_{\text {ideal }} \text { variable } \\
\phi_{\mathrm{k}}=0.01\end{array}$ \\
\hline A & 38.1 & 240 & 156 & 1.10 & 0.70 & 4300 & 2760 \\
\hline$A^{*}$ & 2.0 & 26 & 23 & 0.22 & 0.19 & 15500 & 14000 \\
\hline B & 20.3 & 53 & 33 & 0.20 & 0.12 & 1480 & 890 \\
\hline C & 12.2 & 22 & 20 & 0.08 & 0.07 & 990 & 860 \\
\hline D & 11.2 & 32 & 29 & 0.12 & 0.10 & 1610 & 1340 \\
\hline E & 19.8 & 46 & 36 & 0.17 & 0.13 & 1290 & 990 \\
\hline $\mathrm{F}$ & 9.1 & 14 & 9 & 0.05 & 0.03 & 825 & 500 \\
\hline G & 7.6 & 23 & 9 & 0.09 & 0.03 & 1780 & 590 \\
\hline Cotal & $(\mathrm{L} / \mathrm{min}$ & $205-325 \mathrm{~m}$ & ys: & 1.81 & 1.18 & & \\
\hline
\end{tabular}

Converting flux rates to specific discharge requires an area through which the flow traverses. Using the vertical lengths assigned to the zones shown on Figure 18, the width through which flow occurs is estimated from the characteristic diffusive length of heat conduction:

$w=\sqrt{2 D t}$

where $D$ is the thermal diffusivity and $t$ is time. If we again use the thermal parameters for the Bullfrog tuff, then $D=\alpha / \mathrm{C}_{\mathrm{p}}=6.63 \times 10^{-7} \mathrm{~m}^{2} / \mathrm{s}$. A diffusive flux length for the final thermal profile $w$, acquired 25.5 hours after the start of heating, is $0.35 \mathrm{~m}$. This equation was used to estimate diffusion penetration under one-dimensional conditions. We would expect diffusive penetration under radial conditions to be shorter than for 1-D conditions, although the real situation is further complicated by the presence of borehole completion materials and convective heat removal. By normalizing the specific discharge, calculated as $F / l w$, by the fracture porosity, $\phi_{f}$, the transport velocity can be estimated as:

$v=\frac{F}{\phi_{f} l w}$.

Table 4 provides estimates of groundwater transport velocity, calculated using both the upper and lower bounds for $\Delta \mathrm{T}_{\text {conductive, assumed with either constant or variable thermal }}$ properties. A fracture porosity of 0.01 was assumed, which is considered to be at the upper bound of accepted values for the welded Bullfrog Tuff. The result of these calculations shows that velocities are on the order of $\mathrm{km} / \mathrm{yr}$.

The vertical length over which the temperature change for a flow zone, $\Delta T_{\text {measured }}$, is averaged can change the estimated groundwater velocities. Because fluid transport in the fractured volcanic tuff occurs primarily through discrete fractures, the local minima in temperature may be more indicative of maximum groundwater velocities than the 
average temperature change over a region. As an example, a subsection of Zone "A," called "A*," has been defined for the Borehole 24PB interval from 229 mbgs to 231 mbgs. Table 4 shows that Zone $A^{*}$ exhibits a flux of $0.2 \mathrm{~L} / \mathrm{min}$, resulting in a velocity estimate of $15 \mathrm{~km} / \mathrm{yr}$. Corroborating evidence from 24PB optical televiewer, caliper, natural gamma, gamma density and formation resistivity logs do not indicate any reason to suspect that Zone $\mathrm{A}^{*}$ has greater fracturing or alternative thermal properties than surrounding regions, so the primary assumptions used for calculating velocity $(\phi=0.01$, $\Delta T_{\text {conductive }}=4.46^{\circ} \mathrm{C}$ ) are still considered reasonable. Recommendations for additional work to remove some of the assumptions and reduce uncertainty are made in Section 6.

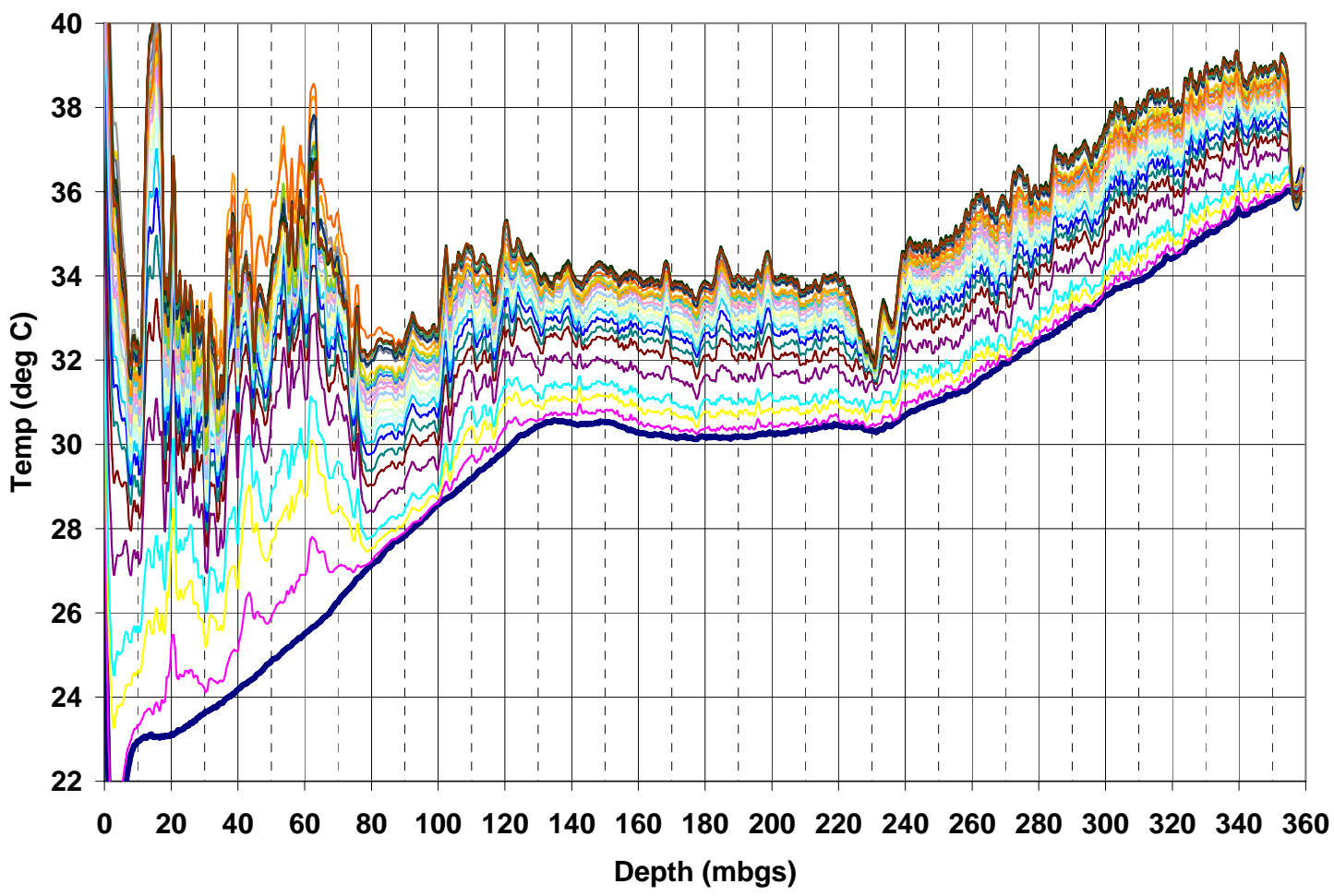

Figure 16. Thermal logs acquired during operation of the DTPS in NC-EWDP24PB. The dark-blue line at the bottom is the baseline temperature profile. All other profiles were taken during heating; the first three profiles were taken at 15-minute intervals, the fourth profile taken $\mathbf{4 5}$ minutes later, and all subsequent profiles at one-hour intervals. 


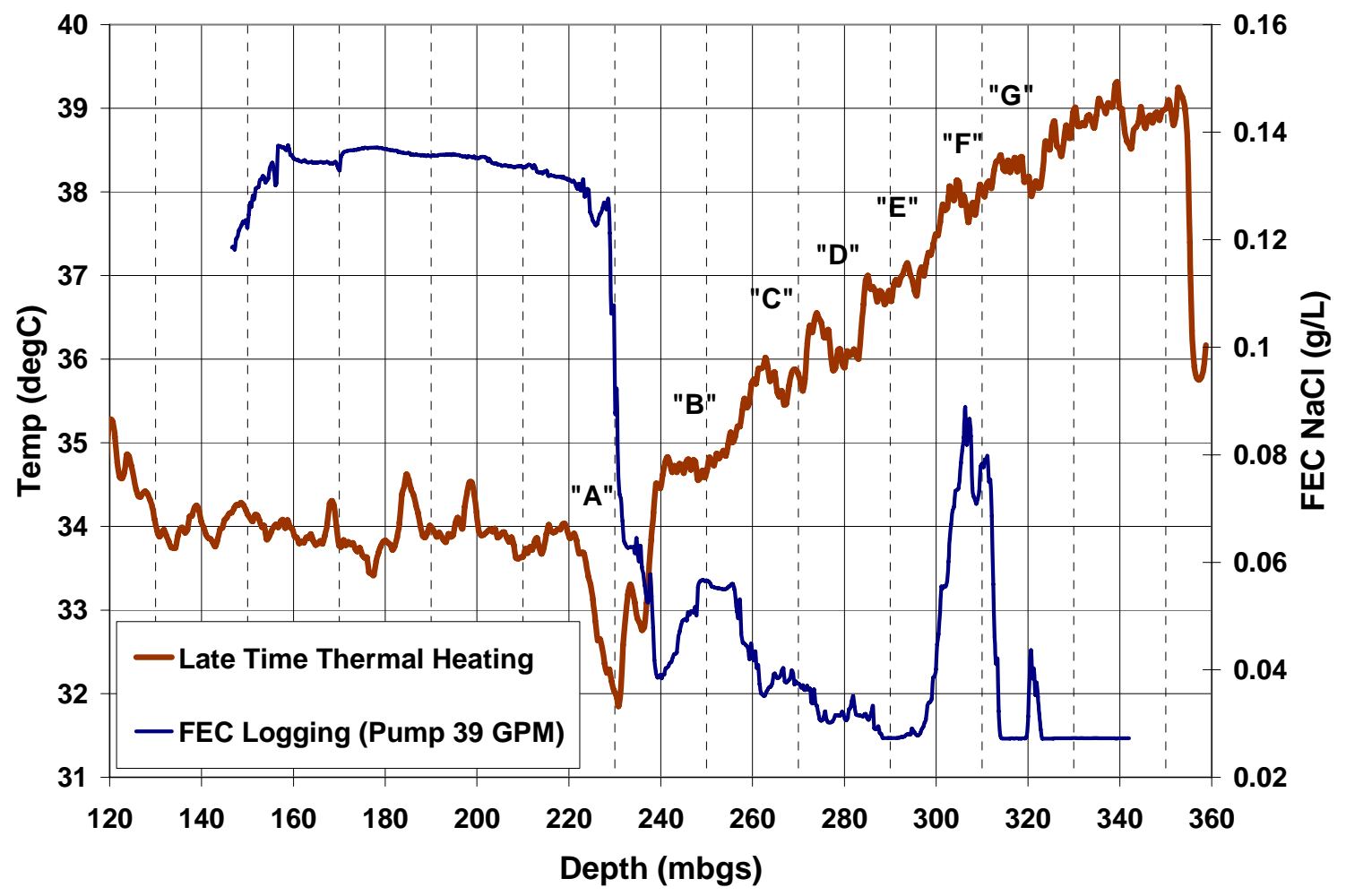

Figure 17. The final thermal heating profile acquired 25.5 hours after the start of heating. The FEC log shown was the final log acquired during FEC Test 5 and was used to help delineate flowing intervals. 


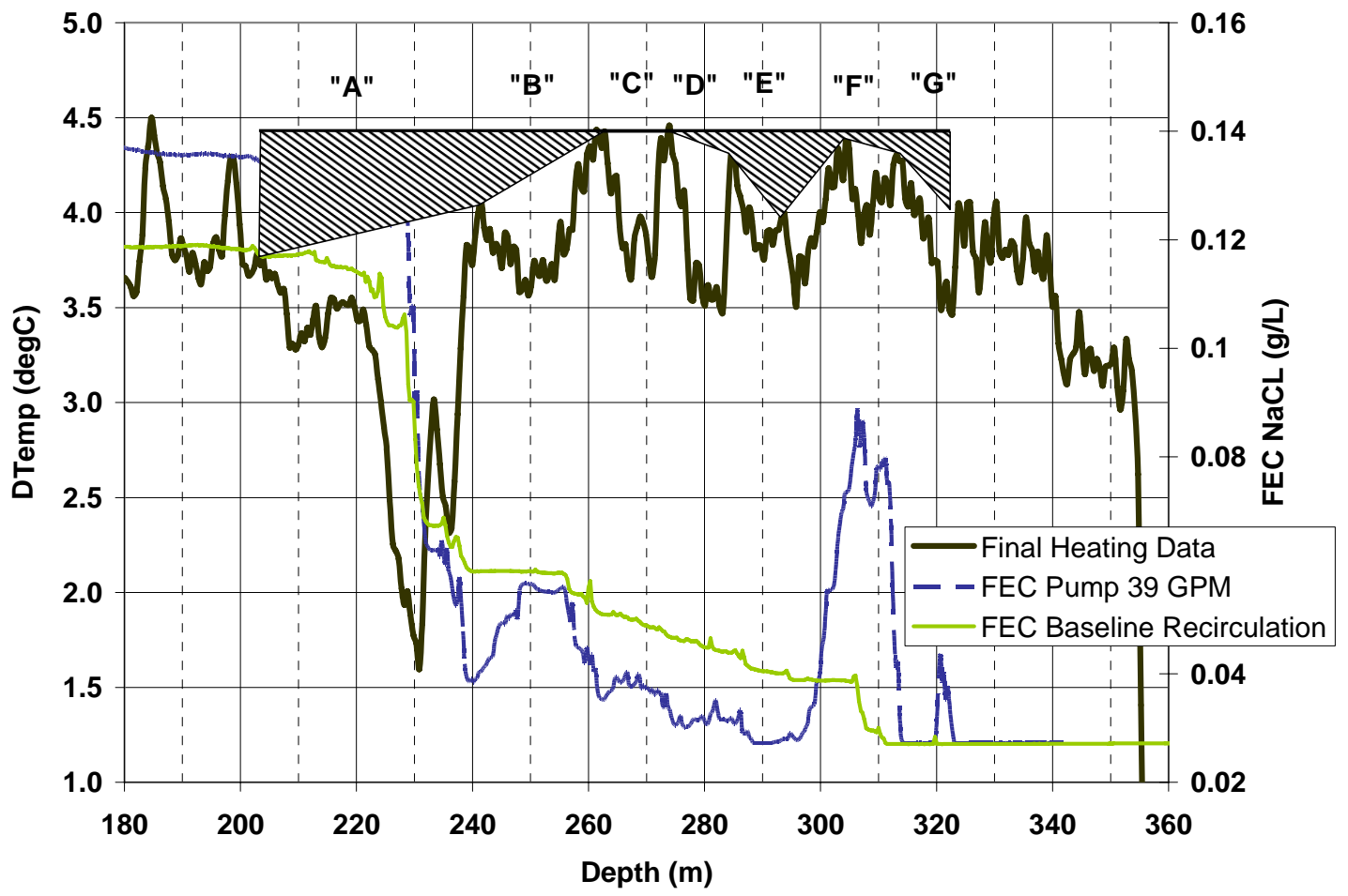

Figure 18. The temperature difference between the baseline thermal profile and the final thermal profile acquired 25.5 hours after the start of heating. The area identified by the hatched polygon represents a range of idealized temperature profiles under no flow conditions. The upper boundary corresponds to the assumption of uniform thermal properties and the lower boundary implies that the flow zones upper and lower boundaries are under no flow conditions. 


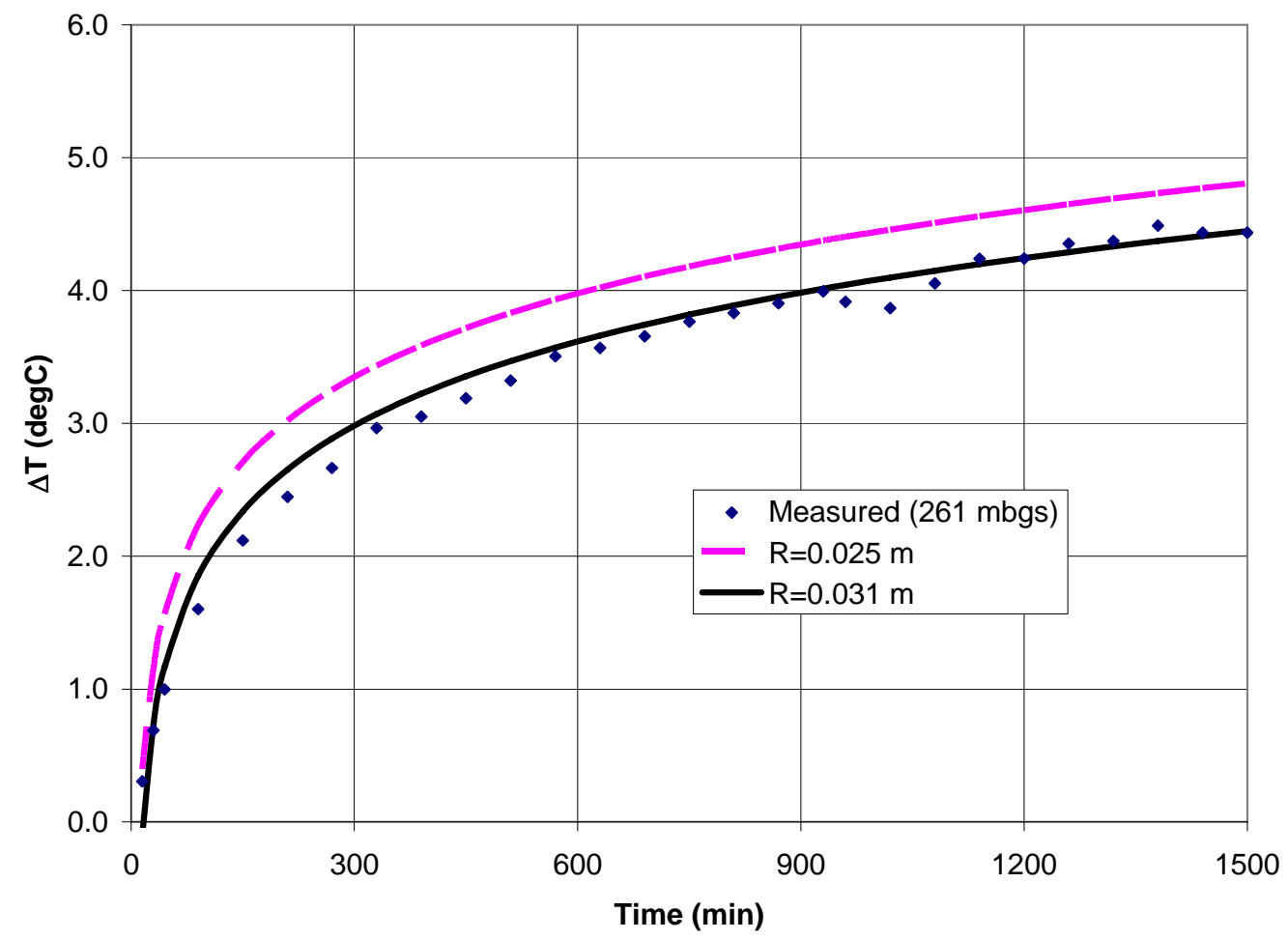

Figure 19. Radial thermal model of 24PB compared to DTPS data acquired at 261 mbgs. Thermal properties are reported Bullfrog formation values.

\section{Buoyancy Effects}

Heating of the borehole and the surrounding formation leads to changes in water density that may trigger unwanted buoyancy effects. To examine whether buoyant forces are substantial enough to induce significant fluid flow, a calculation was performed assuming radial geometry. The difference between the water density at the outer radius of Borehole 24PB $(r=0.085 \mathrm{~m})$ and the density under far-field temperature conditions produced by a temperature difference of $2.5^{\circ} \mathrm{C}$ results in a density change of $\sim 0.75 \mathrm{~kg} / \mathrm{m}^{3}$. The thermal diffusive penetration depth, $l=\sqrt{2 D t}$, is used as the radius of influence in Dupuit's steady-state radial flow solution, modified to account for buoyancy forces:

$\frac{(\rho(r)-\rho(l)) l \sin \theta}{\rho_{\text {water }}}=\frac{Q}{2 \pi T} \ln \frac{r}{l}$

The left-hand side of the equation represents the change in head caused by buoyancy, with the dip angle $\theta$ accounting for the non-vertical orientation of the fractures. Given the transmissivity $\left(T=0.006 \mathrm{~m}^{2} / \mathrm{s}\right)$ of the rocks near Borehole $24 \mathrm{~PB}$ - previously calculated from the 24PB pump test data (see Section 3.2.2) - allows calculation of the unknown fluid flux, $Q$. Assuming that the average fracture dip angle is $45^{\circ}$, we compute a flux of $0.25 \mathrm{~L} / \mathrm{min}$ for the borehole between the water table $(120 \mathrm{mbgs})$ and the base of the permeable upper portion of the Tram tuff (320 mbgs). Scaling this to account for flow 
across the borehole at depths included within Zones "A" through "G," (115 m length) we estimate a flux of $0.14 \mathrm{~L} / \mathrm{min}$, about an order of magnitude smaller than the estimates of natural flux (Table 4). While this calculation shows that buoyancy cannot be ignored, it is beyond this simple analysis to try to further refine the estimates. As we note in the recommendation section (Section 6), a detailed numerical heat and mass transport model would explicitly account for buoyant forces.

\subsection{Discussion of DTPS Data}

Both the FEC and DTPS logs indicate that Borehole 24PB exhibits large fluxes between $220 \mathrm{mbgs}$ to $240 \mathrm{mbgs}$. This depth also is significant because the regional thermal gradient reaches a local minimum at this location. Since FEC logs also provide evidence for an upward gradient, it is reasonable to suspect that deeper fluid upwells to this high flux zone and is then carried downgradient. This would explain the relatively flat temperature profile between the groundwater table at $120 \mathrm{mbgs}$ down to $230 \mathrm{mbgs}$. This idea remains a hypothesis and needs to be supported by models that specifically target the regional system using the FEC and DTPS transport data.

Between $210 \mathrm{mbgs}$ to $340 \mathrm{mbgs}$, regions of flow identified in DTPS logs correlate well with the locations of inflow identified by FEC logging, helping to build confidence in the attribution of heat transport in this region to fluid flux. The interpretation of the thermal logs at depths shallower than $210 \mathrm{~m}$ is problematic, in part because regions of flow and no flow have not been identified by FEC logging. The upward gradient in Borehole 24PB dictates that shallow permeable features are outflow points, which are harder to recognize using FEC logs. To further complicate the interpretation, there are only three small peaks in the DTPS logs - located at depths of $168 \mathrm{mbgs}, 185 \mathrm{mbgs}$, and $198 \mathrm{mbgs}$ - that have

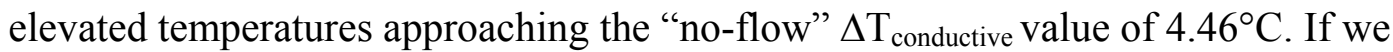
assume that the average $\Delta \mathrm{T}_{\text {conductive }}$ should be $4.46^{\circ} \mathrm{C}$ between $125 \mathrm{~m}$ to $205 \mathrm{~m}$ (as we did in Section 4.2), then the thermal flux due to advective heat loss would be $286 \mathrm{~J} / \mathrm{s}$ for this $80 \mathrm{~m}$ long borehole section. Using the same assumptions as in Section 4.2, Table 4, this would correspond to a flux of $1.1 \mathrm{~L} / \mathrm{min}$, a specific discharge of $20 \mathrm{~m} / \mathrm{yr}$, and a groundwater velocity of $2,000 \mathrm{~m} / \mathrm{yr}$ over the entire zone. However, if the thermal conductivity for this shallower Bullfrog tuff is higher than the deeper part of the unit, then the actual flux through this unit could be significantly less or even zero. Because the FEC data could not corroborate flow through the shallow Bullfrog tuff, these calculated fluxes were not included in Table 4. 


\section{Summary}

Borehole NC-EWDP-24PB (24PB) was drilled and completed in February and March of 2006 by the Nye County Nuclear Waste Repository Project Office. In addition to standard geophysical borehole logs and a pump test, six flowing fluid electrical conductivity logs (FEC) were acquired with multiple recirculation and pumping rates, including runs where the well was shut in (ambient flow FEC logs).

Based on the FEC logs, discrete flow zones can be readily identified, indicating that flow through the fractured units of welded tuffs is highly localized. Preliminary analyses of the FEC logs further indicate that water enters and/or exits Borehole 24PB at relatively high flow rates. These high flow rates (which yield correspondingly high groundwater transport velocities given the discrete flow pattern) may represent ambient flow conditions, or may be affected by internal wellbore flow effects, as indicated by inconsistent results obtained using data from the recirculation, shut-in, and pumping periods.

To avoid the potential effects induced by the presence of an open borehole, a thermal perturbation technique was employed as an alternative method to estimate ambient groundwater flow rates. In this method, the borehole is backfilled, and heat is applied at a constant rate. The transient increase of the borehole temperature can then be analyzed to infer heat removal by advective groundwater flow. The temperature data reveal a largescale flow structure as well as convective heat removal on the scale of individual flow zones, which are consistent with the high-resolution pattern identified by the FEC logs. Moreover, the preliminary analysis of the temperature data corroborates the relatively high fluid flow rates previously inferred by the analysis of the FEC logs, without the uncertainty of open borehole conditions.

The main results of the preliminary analyses can be summarized as follows:

- Fluid flow through the tuff units in the saturated zone near Yucca Mountain is highly localized, with the majority of water being carried along a few highlypermeable features.

- The FEC and thermal logs are an attempt to directly measure groundwater transport through the saturated zone, rather than to rely on flow rates determined from head and permeability estimates.

- The estimated flow rates are on the order of a few liters per minute, resulting in groundwater transport velocities on the order of a few kilometers per year.

- While Borehole 24PB is located within the major (predicted) transport pathway from the proposed repository to the accessible environment, it is important to examine whether this single data point is representative of the regional groundwater flow pattern relevant for the prediction of radionuclide transport. 
These flow rate and transport velocity estimates are based on simplified conceptual models describing fluid flow and heat transfer in the vicinity and within a borehole. While these preliminary analyses yield consistent order-of-magnitude estimates, there are ambiguities and inconsistencies. This calls for a detailed analysis of all available data to reduce the potential risk that the estimates are the result of testing and/or modeling artifacts.

\section{Recommended Future Work}

Given that the preliminary estimates of ambient flow rates and transport velocities are relatively high, and considering the potential impact of high rates and velocities on saturated-zone flow and transport behavior, we recommend that a comprehensive analysis of all the available data be performed. Moreover, additional data sets at other locations should be collected to examine whether the current data set is representative of the regional flow system near Yucca Mountain. Detailed recommendations are given below.

\subsection{FEC Logging}

We have analyzed the ambient-flow FEC logs (Test 1, Test 3 and to less degree Test 6) and also looked at the steady-state recirculation profiles. The major remaining data sets that need to be analyzed are the flowing FEC logs (Tests 2, 4, and 5). If these data can be modeled consistently with the ambient flow logs, we shall have considerably more confidence in the interpretation of the data. Sensitivity studies performed on the conceptual model developed by utilizing the entire FEC data set can provide confidence intervals for the resulting inflow and outflow depths and magnitudes.

The analyses will also provide us with estimates of far-field pressure heads of all the inflow and outflow points through the use of the multiple flow-rate method (Tsang and Doughty, 2003]. These may provide some understanding of the basis for the artificial adjustment process that relates recirculation (which may introduce a pressure gradient up the borehole) to ambient flow conditions, and may ultimately provide valuable insight into the difference between these two conditions. At this time, the difference is very hard to evaluate, because the highly permeable system at the site is very sensitive to small pressure fluctuations.

Other tasks to be done are:

- Undertake an OSTI-LBNL-QIP-SIII.4, Qualification of Unqualified Data, review of the FEC data so that the results may be formally incorporated into the OSTI program.

- Obtain and study the flow rate and pressure head as a function of time during recirculation for Test 5 .

- Use variable formation salinity, based on samples collected but not yet provided.

- Use integral method and group analysis of FEC logs developed at LBNL. The integral method examines the time-variation of the amount of DI water in the entire borehole 
rather than looking at individual peaks. The group method simplifies the analysis by combining feed points into a few major groups. For the present problem, we believe that the fit can probably be done with between 15 and 20 feed points, by ignoring the small feed points (or adding them to the neighboring points) and grouping them based on the results of the DTPS analysis.

- Combine time-dependent feed-point strengths to model recirculation and ambient flow in a single model.

\subsection{DTPS Logging}

Plans are currently underway to acquire qualified thermal logging data using the DTPS at 24PB and in alluvial well 32P. Nye County personnel have been trained in the operation of the DTPS and are actively writing a work plan to guide field activities; an LBNL-TIP is currently under review. Future efforts in 24PB will be qualified under Berkeley Lab's OST\&I QA program, with eventual submittal of data to the TDMS. It is recommended that future tests be extended to at least 48 hours of heating to increase the depth of penetration into the formation, as well as to log both the heating and cooling phases (as was originally planned during the scoping study).

It is also recommended that a numerical mass and heat transport model (e.g., a TOUGH2 model) incorporating the thermal complexity of the borehole be developed to interpret DTPS data. This will reduce uncertainty in the estimation of the thermal flux, since the numerical model would incorporate the thermal properties of the borehole completion materials, the water-filled piezometer, and the layout of the heater and DTS fiber-optic cable. By modeling variably dipping fractures and the density dependence of water on temperature, buoyant forces would be incorporated. Furthermore, the diffusive penetration length assumption $(w=\sqrt{2 D t}$ ) used herein to convert energy fluxes into specific discharge would no longer be required, since fluid flux would be a key component of the model.

It is further recommended that the high-resolution hydrologic information derived from the analysis of the FEC and DTPS logs be synthesized into a single heat and mass transport model to interpret the regional thermal gradient. This model could serve to guide upscaling of the high-resolution information and would serve as a check on the results of the local estimates. Better understanding of the influence of vertical gradients on regional flow may result from the application of this proposed large-scale model.

\subsection{Additional Measurement Locations}

The FEC and DTPS data collected at 24PB represent one location in a very large, complex, highly heterogeneous regional flow system. However, the data's significance should not be overlooked: the FEC logging and DTPS provide direct observations of transport on the spatial scale of individual flow zones (and potentially individual fractures). 
With the current level of understanding of transport processes in the SZ and the large range in estimated groundwater velocities in the site-scale SZ flow model, it is impossible to assess whether the FEC and DTPS data constitute an outlier, or are in fact indicative of the prevailing hydrologic conditions in the volcanics south of the proposed repository. Obtaining additional information at other locations will be needed to make this determination. We therefore propose that two additional sites be selected for carrying out FEC and DTPS studies.

More specifically, one new borehole located $100 \mathrm{~m}$ south-to-southeast of 24PB would facilitate an investigation of local variability in groundwater fluxes. In addition, if a high flow zone corresponding to Borehole 24PB's Zone "A" were identified in the new boring, this would create an opportunity for performing a natural-gradient transport study. Crosshole tracer transport testing under natural gradient conditions is arguably the most accurate method for estimating kinematic porosity and constraining transport velocity estimates. However, the operational difficulty and risk involved has historically limited its applicability. Given the rapid transport observed in the "A" zone, a cross-hole tracer test could be accomplished in weeks, and not years. A second boring to the north, considerably closer to the proposed repository, could be used to assess groundwater fluxes at a location more relevant to the point at which a radionuclide plume would start its migration. This second borehole could test the hypothesis that to the north, groundwater fluxes are smaller, since regional groundwater flux into the Amargosa Valley is thought to be predominantly from the eastern boundary of the site-scale SZ model and in the Fortymile Wash stream channel.

\section{Acknowledgments}

This work was supported by the Director, Office of Civilian Radioactive Waste Management, Office of Science and Technology and International, of the U.S. Department of Energy. The drilling program for Borehole NC-EWDP-24PB was conducted by the Nye County Department of Natural Resources and Federal Facilities, Nuclear Waste Repository Project Office, pursuant to a Cooperative Agreement funded by the U.S. Department of Energy. The authors are appreciative of suggestions and assistance provided by Chin-Fu Tsang, Paul Reimus, Jamie Walker, Raymond Federwisch, Gudmundur Bodvarsson, and Dale Hammermeister, and the careful reviews of this paper by Yvonne Tsang and Kenzi Karasaki.

\section{Disclaimer}

The views and opinions of authors expressed herein do not necessarily state or reflect those of the U.S. Department of Energy. 


\section{References}

Andrea, F., Schrötter, J., Merriam D. F., and Blackwell, D.D., 1997, Application of optical-fiber temperature logging-An example in a sedimentary environment, Geophysics, Volume 62, Issue 4, pp. 1107-1113.

Arps, J.J., 1953, The effect of temperature on the density and electrical resistivity of sodium chloride solutions. Trans. AIME, 98:327-328.

Ballard, S. 1996. The in situ permeable flow sensor: A groundwater flow velocity meter. Ground Water. v. 34(2).

Bredehoeft, J.D. and Papadopulos, I.S., 1965, Rate of vertical movement estimated from the earth's thermal profile, Water Resour. Res., 1:325-328.

Doughty, C. and C.-F. Tsang, BORE II - A code to compute dynamic wellbore electrical conductivity logs with multiple inflow/outflow points including the effects of horizontal flow across the well, Rep. $L B L-46833$, Lawrence Berkeley National Laboratory, Berkeley, CA, 2000.

Doughty, C. and C.-F. Tsang, Signatures in flowing fluid electric conductivity logs, J. of Hydrology, 310, 157-180, 2005.

Doughty, C., S. Takeuchi, K. Amano, M. Shimo, and C.-F. Tsang, Application of multirate flowing fluid electric conductivity logging method to Well DH-2, Tono Site, Japan, Water Resour. Res., 41, W1041, (10.1029/2004WR003708), 2005.

Drury, M.J. and Lewis, T.J., 1983, Water movement within Lac du Bonnet Batholith as revealed by detailed thermal studies of three closely-spaced boreholes, Techtonophysics, 95, pp. 337-351.

Drury, M.J., 1984, Borehole temperature logging for the detection of water flow, Geoexploration, v. 22, 231-243.

Förster, A., Schrötter, J., Merriam, D.F., and Blackwell, D.D., 1997, Appliction of optical-fiber temperature logging - An example in a sedimentary environment, Geophysics, v. 62(4) 1107-1113.

Hale, F.V. and C.-F. Tsang, A code to compute borehole conductivity profiles from multiple feed points, Rep. LBL-24928, Lawrence Berkeley Laboratory, Berkeley, Calif., 1988.

Jessop, A.M., 1987, Estimation of lateral water flow in an aquifer by thermal logging, Geothermics, v. 16, 2, pp. 117-126.

Kukkonen, I., Suppala, I., Korpisalo, A., Koskinen, T., 2005, TERO borehole logging device and test measurements of rock thermal properties in Olkiluoto, POSIVA OY, Geological Survey of Finland, Report 2005-09 
Safanda, J., Heidinger P., Wilhelm, H. and Cermák, V., 2005, Fluid convection observed from temperature logs in the karst formation of the Yucatán Peninsula, Mexico, $J$. Geophys. Eng. v. 2, 326-331 doi:10.1088/1742-2132/2/4/S05

Su, G.W., B.M. Freifeld, C.M. Oldenburg, P.D. Jordan, and P.F. Daley, 2006, Interpreting velocities from heat-based flow sensors by numerical simulation, Ground Water, v. 44, 386-393, doi:10.1111/j.1745-6584.2005.00147.x

Tsang, C.-F. and C. Doughty, 2003, Multirate flowing fluid electric conductivity logging method, Water Resour. Res., 39(12), 1354.

Tsang, C.-F., P. Hufschmeid, and F.V. Hale, 1990, Determination of fracture inflow parameters with a borehole fluid conductivity logging method, Water Resour. Res., 26(4), $561-578$. 